\title{
Physical robustness of canopy temperature models for crop heat stress simulation across environments and production conditions
}

Heidi Webber ${ }^{1}$, Jeffrey W. White ${ }^{2}$, Bruce A. Kimball ${ }^{2}$, Frank Ewert ${ }^{1,3}$, Senthold Asseng ${ }^{4}$, Ehsan Eyshi Rezaei $^{1,5}$, Paul J. Pinter Jr. ${ }^{6}$, Jerry L. Hatfield ${ }^{7}$, Matthew P. Reynolds ${ }^{8}$, Behnam Ababaei ${ }^{9}$, Marco Bindi ${ }^{10}$, Jordi Doltra $^{11}$, Roberto Ferrise ${ }^{10}$, Henning Kage ${ }^{12}$, Belay T. Kassie ${ }^{4}$, Kurt-Christian Kersebaum ${ }^{3}$, Adam Luig $^{12}$, Jørgen E. Olesen ${ }^{13}$, Mikhail A. Semenov ${ }^{14}$, Pierre Stratonovitch ${ }^{14}$, Arne M. Ratjen ${ }^{12}$, Robert L. LaMorte $^{2}$, Steven W. Leavitt ${ }^{15}$, Douglas J. Hunsaker ${ }^{2}$, Gerard W. Wall ${ }^{2}$, Pierre Martre ${ }^{9}$

${ }^{1}$ University of Bonn, Institute of Crop Science and Resource Conservation (INRES), Crop Science Group, Katzenburgweg 5, 53115 Bonn, Germany

${ }^{2}$ U.S. Arid-Land Agricultural Research Center, USDA, Agricultural Research Service, 21881 North Cardon Lane, Maricopa, Arizona, 85138, USA

${ }^{3}$ Leibniz Centre for Agricultural Landscape Research (ZALF), 15374 Müncheberg, Germany

${ }^{4}$ Agricultural \& Biological Engineering Department, University of Florida, Gainesville, FL 32611, USA

${ }^{5}$ Center for Development Research (ZEF), Walter-Flex-Straße 3, 53113 Bonn, Germany

${ }^{6}$ USDA-ARS, Retired Research Biologist. Phoenix, Arizona, USA

${ }^{7}$ USDA-ARS National Laboratory for Agriculture and the Environment, Ames, IA, USA

${ }^{8}$ CIMMYT, Int. Apdo. Postal 6-641, 06600 Mexico, DF, Mexico

${ }^{9}$ UMR LEPSE, INRA, Montpellier SupAgro, 34060 Montpellier, France

${ }^{10}$ University of Florence, DiSPAA, Piazzale delle Cascine 18, 50144 Firenze, Italy

${ }^{11}$ Cantabrian Agricultural Research and Training Centre, CIFA, c/Héroes 2 de Mayo 27, 39600 Muriedas, Cantabria, Spain

${ }^{12}$ Christian-Albrechts-University, Institute of Crop Science and Plant Breeding, Hermann-RodewaldStr. 9, 24118 Kiel, Germany 
${ }^{13}$ Department of Agroecology, Aarhus University, Blichers Allé 20, PO Box 50, 8830 Tjele, Denmark

${ }^{14}$ Computational and Systems Biology Department, Rothamsted Research, Harpenden, Herts, AL5 2JQ, United Kingdom of Great Britain and Northern Ireland

${ }^{15}$ Laboratory of Tree Ring Research, University of Arizona, Tucson, Arizona 85721, USA

Heidi Webber

+49228736849

hwebber@uni-bonn.de

heidi.webber@mail.mcgill.ca

Keywords: heat stress; crop model improvement; heat and drought interactions; climate change impact assessments; canopy temperature; wheat

\begin{abstract}
Despite widespread application in studying climate change impacts, most crop models ignore complex interactions among air temperature, crop and soil water status, $\mathrm{CO}_{2}$ concentration and atmospheric conditions that influence crop canopy temperature. The current study extended previous studies by evaluating $T_{c}$ simulations from nine crop models at six locations across environmental and production conditions. Each crop model implemented one of an empirical (EMP), an energy balance assuming neutral stability $(\mathrm{EBN})$ or an energy balance correcting for atmospheric stability conditions (EBSC) approach to simulate $T_{\mathrm{c}}$. Model performance in predicting $\mathrm{T}_{\mathrm{c}}$ was evaluated for two experiments in continental North America with various water, nitrogen and $\mathrm{CO} 2$ treatments. An empirical model fit to one dataset had the best performance, followed by the EBSC models. Stability conditions explained much of the differences between modeling approaches. More accurate simulation of heat stress will likely require use of energy balance approaches that consider atmospheric stability conditions.
\end{abstract}




\section{Introduction}

As temperatures warm with climate change, reductions in crop yields due to heat stress (Porter and Gawith, 1999; Wheeler et al., 2000) are expected to increase (Porter et al., 2014). Statistical models of crop yield response to weather have detected large yield declines across many regions as the number of days with extremely high temperature have increased (Lobell et al., 2011; Hawkins et al., 2013; Lobell et al., 2013; Hatfield, 2016). Heat stress depends on unique combinations of the timing and duration of high temperature events, crop phenological stage and varietal characteristics (Rezaei et al., 2015; Prasad et al., 2017), suggesting that process-based crop models may provide valuable insights into how high temperatures impact crop performance under climate change (White et al., 2011). It is only recently that process-based crop models have included heat stress effects on grain number, grain yield or crop senescence (Challinor et al., 2005; Asseng et al., 2011; Moriondo et al., 2011; Maiorano et al., 2017), with limited evaluation of their performance under heat stress conditions (Stratonovitch and Semenov, 2015; Gabaldón-Leal et al., 2016). Further, unlike their statistical counterparts, most process-based crop models do not account directly for the interaction of crop water status and high temperature events (Lobell and Asseng, 2017), although such interactions affect the magnitude of heat stress (Gourdji et al., 2013; Anderson et al., 2015; Troy et al., 2015). Recent efforts have estimated and evaluated canopy temperature $\left(T_{c}\right)$ simulations in process-based crop models (Webber et al., 2016b; Webber et al., 2017), though with their evaluation limited to irrigated production in arid conditions. Canopy temperature has long been considered in irrigation scheduling (Jackson et al., 1977) and is used as a selection trait for drought and heat tolerance (Blum et al., 1982; Hatfield et al., 1987; Blum et al., 1989; Reynolds and Langridge, 2016). Typically, crops with cooler canopies maintain higher yields under water deficits or with heat stress under irrigated conditions (Blum et al., 1982; Blum et al., 1989; Olivares-Villegas et al., 2007; Lopes and Reynolds, 2010; Pinto and Reynolds, 2015), while Pinter et al. (1990) offer a slightly different interpretation. 
The canopy temperature of crops generally follows ambient air temperature $\left(T_{\text {air }}\right)$ but can drop below or rise above $T_{\text {air }}$ due to the balance of radiative heating and transpirational cooling. The difference between $T_{c}$ and $T_{\text {air }}$, termed canopy temperature depression $\left(\Delta T=T_{c}-T_{\text {air }}\right)$ is larger and more negative with ample soil water supply and high vapor pressure deficit (VPD) (Idso et al., 1981; Jackson et al., 1981). Any factor which reduces the rate of transpiration, such as soil water deficit (Idso et al., 1981), low reference crop evapotranspiration $\left(\mathrm{ET}_{\mathrm{o}}\right)$, typically driven by low VPD, or elevated atmospheric $\mathrm{CO}_{2}$ concentrations (Kimball et al., 1999; Wall et al., 2000; Leakey et al., 2006; Wall et al., 2006; Gray et al., 2016) will reduce canopy cooling. When transpiration is restricted, $T_{c}$ frequently exceeds $T_{\text {air }}$ (Siebert et al., 2014).

Despite the importance of $T_{c}$ for irrigation management and crop breeding, the complexity of calculations of $T_{c}$ has likely discouraged wider application of $T_{c}$ in crop models. Canopy temperature results from the energy balance at the crop surface, in which energy fluxes include net radiation, sensible and latent heat transfer as well as energy transfer with soils (Jackson et al., 1981). Beyond the complexity of stomatal regulation of gas exchange and its role in determining latent energy flux together with atmospheric evaporative demand (Jarvis and McNaughton, 1986), the stability of the air influences aerodynamic resistance, $r_{\mathrm{a}}$, of the transfer of heat and vapor between the crop surface and the atmosphere (Monteith and Unsworth, 2007). For example, under stable atmospheric conditions, air near the canopy is heavier than the overlaying air such that buoyancy is inhibited and the aerodynamic resistance to heat and vapor transfer are relatively greater, whereas in unstable conditions, buoyancy of the air near the crop canopy reduces $r_{a}$ (Monteith and Unsworth, 2007). The Monin-Obukhov Similarity Theory (MOST) is a common approach to determine $r_{a}$ in which stability correction factors (Thom, 1975) are applied to logarithmic momentum, temperature and vapor fluxes (Monin and Obukhov, 1954), and consistitutes the main approach to energy balance correcting for atmospheric stability conditions (EBSC). However, stability corrections depend on $T_{c}$ among other factors (Webb, 1970), implying that a solution of $T_{c}$ using an EBSC approach requires an iterative solution (Liu et al., 2007). Two main alternatives avoid the complexity of correcting for boundary layer stability. The first assumes neutral stability conditions and solves a 
relatively straightforward energy balance (EBN) (Clawson et al., 1989), though the method implicitly assumes that $T_{c}$ is close to $T_{\text {air }}$. The second option avoids an energy balance by using an empirical relationship (EMP) to relate $T_{c}$ to main drivers, such as $T_{\text {air }}$, VPD and soil water status. The EMP methods have produced estimates of $T_{c}$ similar to those of the EBSC methods for $r_{a}$ (Liu et al., 2007) and $T_{c}$ (Webber et al., 2017), but both studies noted that their results needed to be validated across a wider range of climates and growing conditions.

The main objective of this study was to assess the skill of different crop models in simulating $T_{c}$ for a wide range of environmental conditions (locations, years, atmospheric $\mathrm{CO}_{2}$ concentrations) and agronomic conditions (irrigated and rainfed, high and low nitrogen fertilization levels), extending a previous study which considered only potential production conditions under ambient $\mathrm{CO}_{2}$ at one location. A second objective was to understand possible strengths of the different approaches for modeling $T_{c}$. The study is undertaken as part of the overall efforts of the Agricultural Model Intercomparison and Improvement Project (AgMIP; Rosenzweig et al., 2013) Wheat group (http://www.agmip.org/wheat/) to understand the impacts of high temperature on wheat yields.

\section{Materials and Methods}

\section{Site and field experiment descriptions}

Data from two series of experiments, here referred to as "FACE-Maricopa" and "China Wheat" were used to evaluate $T_{c}$ simulations (Fig. 1). In the FACE-Maricopa dataset, a spring wheat (Triticium aestivum L.) cultivar was grown over four seasons with buried drip irrigation, ample optimal nitrogen and water regimes, and both ambient and elevated atmospheric $\mathrm{CO}_{2}$ concentrations (Kimball et al., 1999; Kimball et al., 2017) In 1993 and 1994, an additional treatment was a limiting water supply (50\% of the ample water treatment), and in 1996 and 1997, a limited nitrogen treatment was included. In total, 16 experimental treatments were available from the FACE-Maricopa experiments. The China Wheat dataset considered in 
this study is a subset of the larger China Wheat dataset described in Reginato et al. (1988), which investigated winter wheat growth and development across a transect of five sites in North America (Fig. 1) over two growing seasons (harvest years 1985 and 1986). Our analyses focus on data for one cultivar, two water availability levels (rainfed and full irrigation) and one soil nitrogen level (near optimal for plant growth). In total, 18 experimental treatments were obtained from the China Wheat study.

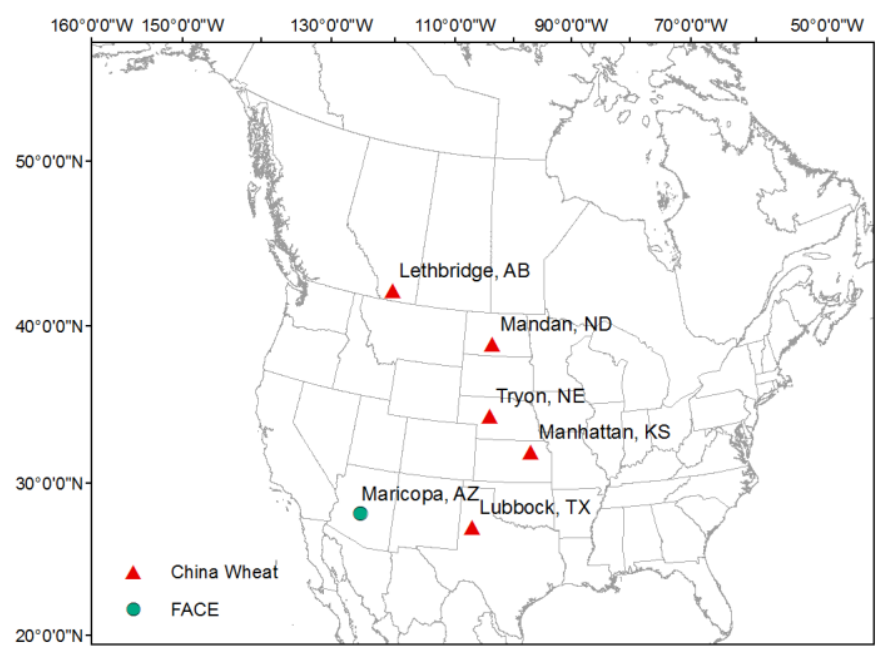

Figure 1. Location of the FACE-Maricopa experiment and the five sites of the China Wheat experiment considered in this study

\section{FACE-Maricopa experiment}

The FACE-Maricopa experiment (Kimball et al., 1995; Hunsaker et al., 1996; Hunsaker et al., 2000) was conducted at Maricopa, AZ, U.S.A. (33.1 ${ }^{\circ} \mathrm{N}, 112.0^{\circ} \mathrm{W} ; 361 \mathrm{~m}$ a.s.1.) between 1993 and 1997. The soil is classified as a reclaimed, Trix clay loam, described in Kimball et al. (1999) as a fine-loamy, mixed (calcareous), hyperthermic Typic torrifluvents. The spring wheat cultivar Yecora Rojo was grown with a mid-December sowing date in each year in east-west rows, $0.25 \mathrm{~m}$ apart with an average plant density of 150 plants $\mathrm{m}^{-2}$. Pest and weed controls were conducted to minimize damage. Plants were sampled weekly for crop height, phenology (Haun (1973) index and Zadoks (1974) stages of development), green leaf area index (LAI), green stem area index, and biomass of crown, stem, leaf, and grain components were 
assessed at 7 to 10 day intervals. Final grain yield measurements were from $20 \mathrm{~m}^{2}$ samples collected with machine harvesting from each plot in late May (Kimball et al., 2017).

To inject $\mathrm{CO}_{2}$ into the plots, $25-\mathrm{m}$ diameter rings of $0.305 \mathrm{~m}$ pipe were placed in the field shortly after planting. Vertical pipes of $2.5 \mathrm{~m}$ height were spaced around the rings at $2.4 \mathrm{~m}$ spacing, and blowers delivered $\mathrm{CO}_{2}$-enriched air through the pipes to the plots out of tri-directional holes at approximately canopy height. Wind and $\mathrm{CO}_{2}$ sensors near the center of the plots were used as inputs to control the flow rate of $\mathrm{CO}_{2}$ such that near-target $\mathrm{CO}_{2}$ levels were maintained throughout the growing season (Hendrey, 1993). The target $\mathrm{CO}_{2}$ levels for the 1993 and 1994 harvest years were 550 ppm, whereas for the 1996 and 1997 harvest years, the $\mathrm{CO}_{2}$ levels were maintained at approximately $200 \mathrm{ppm}$ above ambient, which was approximately 360 ppm (Kimball et al., 1995). All FACE plots had blowers, whereas in 1993 and 1994, there were no blowers in the ambient- $\mathrm{CO}_{2}$ plots. In 1996 and 1997, both FACE and ambient plots had blowers. Pinter et al. (2000) reported that at night the blowers increased $T_{a i r}$ and $T_{c}$ temperatures about $1.0^{\circ} \mathrm{C}$ compared to plots with no blowers, whereas during daytime, there was no effect of the blowers on $T_{c}$ and a slight $\left(-0.2^{\circ} \mathrm{C}\right)$ cooling of $T_{a}$. The increased temperatures associated with the blowers also apparently accelerated plant development such that anthesis was 4 days earlier, and senescence was similarly advanced compared to plots with no blowers.

Irrigation water was applied using a sub-surface drip system installed at $0.23 \mathrm{~m}$ depth (Hunsaker et al., 1996). The full-irrigation treatments received irrigation water to return the root zone soil water content to field capacity whenever the available soil water reached 30\% depletion. For the experiment in 1993 harvest year, the semi-irrigated treatment received $50 \%$ of the water applied to the full irrigation treatment, whereas in the 1994 harvest year experiment, the semi-irrigated treatments received the same amount of water as the full irrigation treatment on every second application date. In the 1996 and 1997 harvest year experiments, all treatments received full irrigation (Hunsaker et al., 1996; Hunsaker et al., 2000). 
Adequate nitrogen was applied to all plots in the 1993 and 1994 harvest year experiments at a rate of 271 and $261 \mathrm{~kg} \mathrm{~N} \mathrm{ha}^{-1}$, respectively (Hunsaker et al., 1996). In the 1996 and 1997 harvest year experiments, nitrogen was applied at a rate of $350 \mathrm{~kg} \mathrm{~N} \mathrm{ha}^{-1}$ to the high $\mathrm{N}$ plots and at a rate of $70 \mathrm{~kg} \mathrm{~N} \mathrm{ha}^{-1}(1996)$ and $15 \mathrm{~kg} \mathrm{~N} \mathrm{ha}^{-1}$ (1997) in the low $\mathrm{N}$ treatments, respectively. There was an addition of 30 and $33 \mathrm{~kg} \mathrm{~N}^{-1}$ applied to the high and low $\mathrm{N}$ plots due to the $\mathrm{N}$ in the irrigation water (Kimball et al., 1999).

Hand-held infrared thermometers (IRTs; Model 110, 15 ${ }^{\circ}$ field-of-view, Everest Interscience, Tucson, Arizona, USA) were used to measure midday $T_{c}$. Almost all of the $T_{c}$ data used for this model intercomparison study were collected between 13:00 and 14:00 (mean solar time) from all plots generally two to five times per week from before emergence until harvest. Occasionally measurements were made at other time, though in this study only observations after 11:30 and before 15:00 were considered. The measurements were obtained from a walkway along the west side of the non-destructively sampled final harvest area in each plot. The IRTs were pointed toward the north at an angle of $20^{\circ}$ below horizontal. At each plot, six measurements were obtained along the walkway. Plot averages were used in this study. Before and after each measurement run, the IRTs were pointed at a black-body source in the shade, and calibration measurements were obtained. Also, before and after each run, air dry and wet bulb temperatures were obtained with a psychrometer, and weather and data quality conditions were noted. Observations of $T_{c}$ used in this study were based on selecting measurements when the IRT was sensing only crop canopy and not soil surface yet senescence had not started, based on results reported in Fig. 6 of Pinter et al. (2000) and Table 1 of Kimball et al. (1999).

Solar radiation, air dry and wet bulb temperatures, rainfall, and windspeed were measured at weather station located near the center of the field. No adjustments were made for night-time blower effects. Time series of the daily maximum air temperatures and canopy temperatures during the four growing seasons are shown in Fig. 2. 


\section{China Wheat experiment}

The China Wheat experiment (named because originally there was a US collaboration with Chinese scientists in this experiment) was conducted along a transect at Lubbock, $\mathrm{TX}\left(33.63^{\circ} \mathrm{N}, 101.83^{\circ} \mathrm{W}\right.$, elev. $1830 \mathrm{~m}$ a.s.1.) on soils classified as a Olton Clay Loam, Manhattan, $\mathrm{KS}\left(39.09^{\circ} \mathrm{N},-96.37^{\circ} \mathrm{W}\right.$, elev. $321 \mathrm{~m}$ a.s.1.) on a Muir silt loam, Tryon, $\mathrm{NE}\left(41.6^{\circ} \mathrm{N}, 100.8^{\circ} \mathrm{W}, 975 \mathrm{~m}\right.$ a.s.1.) on a Valentine fine sand, Mandan, $\mathrm{ND}\left(46.8^{\circ} \mathrm{N}, 100.9^{\circ} \mathrm{W}, 549 \mathrm{~m}\right.$ a.s.1.), a Williams loam and Lethbridge, $\mathrm{AB}\left(49.7^{\circ} \mathrm{N}, 112.8^{\circ} \mathrm{W}, 920 \mathrm{~m}\right.$ a.s.1.) on Lethbridge silty clay loam. Details of the individual experiments were provided by Reginato et al. (1988) and accompanying papers. Time series of the daily maximum temperature at each site for the growing season in the two experimental harvest years are shown in Figs. 3 and 4. The winter wheat cultivar Colt was planted at each site with a row spacing of 0.15 to $0.30 \mathrm{~m}$ in north-south rows. Each plot measured at least $2 \mathrm{~m}$ long with variable width. Weeds and pests were controlled to minimize damage. Nitrogen fertilizer was applied as $\mathrm{NO}_{3}$ at a rate to obtain a near optimal supply of nitrogen availability of $160 \mathrm{~kg} \mathrm{~N} \mathrm{ha}^{-1}$ including soil available nitrogen determined from soil sampling prior to planting to a depth of $1.2 \mathrm{~m}$. Other fertilizers were applied to avoid any nutrient deficiencies. At each site, rainfed and wellwatered treatments were provided. The rainfed treatment relied on rainfall and necessary small irrigations at the time of planting or to prevent crop failure. The well-watered treatment received irrigations to maintain a high water content in the soil profile during the growing season. Irrigations were scheduled to allow for up to a $50 \%$ depletion of plant readily available water from the rooted profile, as determined with neutron probe soil moisture measurements.

Plant-development stages were recorded weekly using both the Haun and the Zadok scales. Crop height was measured on 10 plants per plot usually at a 7 to 14 day frequency. On the same dates, crop biomass was determined from samples of 12 plants per plot selected equally from four sections of the plot. Leaf green area and the area of dead leaves were determined on a subsample of these 12 plants. At maturity, grain yield and final total above ground biomass was determined in an area of at least $3 \mathrm{~m}^{2}$. The $T_{c}$ 
observations were the average of east and west oblique facing measurements (six in each direction) made with handheld infrared thermometers (Everest Interscience or Telatemp, depending on availability at each site) with a bandpass of $8-14 \mu \mathrm{m}$ and a $4^{\circ}$ field of view. Measurements used in this study were taken between 12:00 and 15:00. The frequency with which $T_{c}$ values were available varied between sites and is indicated in Figs. 3 and 4. Values were restricted to $T_{c}$ observations where the crop canopy was sufficiently developed, leaf area index $(\mathrm{LAI})>0.6$, to avoid bias from including soil surface in the instrument field of view. However, as not all sites had LAI time series, Tc values were additionally removed if rainfed $T_{c}$ was much cooler than irrigated $T_{c}$ or if irrigated plots were much hotter than air near the start of spring and no models came close to capturing the response.

\section{Simulation experiment}

Simulations were conducted for the 34 experimental treatments from the two experiments. The study considered nine crop models that differed in terms of their structure and parameterization of both crop growth and development, water, nitrogen and $\mathrm{CO}_{2}$ responses, and their approach to simulate $T_{c}$ (Table 1). Three models used an empirical (EMP) approach to simulate $T_{c}$ (DN, FA and HU). Four models used an energy balance assuming neutral stability atmospheric conditions (HE, S2, SQ, and SS), while the remaining two models (L5 and SP) used an energy balance approach that corrected for atmospheric stability. All models used $T_{\mathrm{c}}$ to drive the heat stress responses (Webber et al., 2017), in some cases including feedback on $T_{c}$ through impacts on crop LAI and height. Heat stress responses varied among the models based on the processes they consider, though all considered at least one of the following mechanisms: reduction in grain number, final grain size, or harvest index, accelerated senescence leading to shorter grain filling period. Further, the sensitive periods, high temperature thresholds and parameterization of heat stress responses differed among models (Table 1).

Simulations were conducted in two steps. In the first step, all available soil moisture and crop response data (LAI, biomass, and grain yield) and a limited amount of $T_{c}$ data ( $T_{c}$ observations for two treatments 
per experiment) were provided to the modelers to calibrate their models. To reduce effects of poor simulations of phenology, anthesis and physiological maturity dates were calibrated to within 5 days for each treatment, so phenology parameters for a given model may have differed among treatments. In the second step, modelers were given all available $T_{\mathrm{c}}$ observations to calibrate their $T_{\mathrm{c}}$ models. Only HU, SP, and L5 used $T_{\mathrm{c}}$ data for calibration, as the other models had no parameters to calibrate their $\mathrm{T}_{\mathrm{c}}$ simulations (Table 1). The results presented in the main text are all based on the results of the calibrated models with additional results from the uncalibrated step in the SI materials. The HU model was treated as a reference for this study, and its results were considered separately from the other EMP models because the parametrization of the routine for maximum $T_{\mathrm{c}}$ (Neukam et al. 2016) was based on a subset of the available data of this study (Table 1) and all data are for continental North America. The underlying multiple linear regression model uses different parameter sets for pre- and post-heading phase to derive maximum $T_{\mathrm{c}}$ as a function of daily incoming global radiation, leaf area index, daily maximum air temperature $\left(T_{\max }\right)$ and the ratio of actual and potential transpiration times the daily mean VPD. The $T_{\mathrm{c}}$ algorithms used in DN and FA were developed with independent datasets. 
Table 1. Descriptions of model components related to canopy temperature $\left(T_{\mathrm{c}}\right)$ simulation and the sensitivity of $T_{\mathrm{c}}$ simulations to water and nitrogen, as well as atmospheric $\mathrm{CO}_{2}$ concentration. The main approach to simulating $T_{\mathrm{c}}$ is indicated as an empirical (EMP), an energy balance assuming neutral stability (EBN) or an energy balance correcting for atmospheric stability conditions (EBSC). NA indicates non-applicable

\begin{tabular}{|c|c|c|c|c|c|}
\hline $\begin{array}{l}\text { Model (2- } \\
\text { letter code; } \\
\text { references) }\end{array}$ & $T_{\mathrm{c}}$ approach & $\begin{array}{l}\text { Possible feedbacks of } \\
\text { water stress on } T_{c}\end{array}$ & $\begin{array}{l}\text { Possible feedbacks of } \\
\text { N on } T_{c}\end{array}$ & $\begin{array}{l}\text { Possible } \\
\text { feedbacks of } \\
\mathrm{CO}_{2} \text { on } T_{\mathrm{c}}\end{array}$ & $\begin{array}{l}\text { Calibration to } \\
T_{c} \text { observations }\end{array}$ \\
\hline $\begin{array}{l}\text { HUMEWheat } \\
\text { (HU, Johnen } \\
\text { et al., 2012; } \\
\text { Ratjen and } \\
\text { Kage, 2015) }\end{array}$ & $\begin{array}{l}\text { REF - EMP } \\
\text { A statistical approach is used to determine } \\
\text { regression models for daily minimum, mean and } \\
\text { maximum } T_{\mathrm{c}} \text { as described in Neukam } \text { et al. } \\
\text { (2016). } T_{\mathrm{c}} \text { observations in this study were } \\
\text { considered to be the daily maximum. } \\
\text { During pre- and post-heading phase different } \\
\text { parameter sets for the covariates ( } p_{1}, p_{2}, p_{3}, p_{4}, \\
\left.\text { and } \mathrm{p}_{5}\right) \text { are used in the multiple linear regression } \\
\text { model to predict daily maximum } T_{\mathrm{c}}\left(T_{\mathrm{c}, \text { max }}\right) \text { : } \\
T_{c, \text { max }}=p_{1}+p_{2} R_{\text {inc }}+p_{3} T_{a, \text { max }}+\end{array}$ & $\begin{array}{l}\text { The ratio of actual to } \\
\text { potential transpiration } \\
\text { quantifies drought stress } \\
\text { and is considered in the } \\
\text { multiple linear regression } \\
\text { model to predict mean } \\
\text { and maximum } T_{\mathrm{c}} \\
\text { (Neukam et al., 2016) as } \\
\text { well as a reduced LAI } \\
\text { development in presence } \\
\text { of drought (Ratjen et al., } \\
2016 \text { ). }\end{array}$ & $\begin{array}{l}\text { N deficit reduces LAI } \\
\text { development (Ratjen } \\
\text { and Kage, 2016) } \\
\text { which is considered in } \\
\text { the soil water balance } \\
\text { calculation and } \\
\text { multiple linear } \\
\text { regression model to } \\
\text { predict mean and } \\
\text { maximum } T_{\text {c. }}\end{array}$ & $\begin{array}{l}\text { Elevated } \mathrm{CO}_{2} \\
\text { decreases } \\
\text { transpiration } \\
\text { rates. The decline } \\
\text { in transpiration in } \\
\text { comparison to } \\
\text { ambient } \mathrm{CO}_{2} \\
\text { (380 ppm) } \\
\text { conditions } \\
\text { accounts for the } \\
\text { change of } \\
\text { minimum, mean }\end{array}$ & $\begin{array}{l}\text { The ambient } \mathrm{CO}_{2} \mathrm{C} \\
\text { FACE-Maricopa d } \\
\text { observations when } \\
\text { the range of }-5 \text { to } 5 \\
\text { for calibration. }\end{array}$ \\
\hline
\end{tabular}




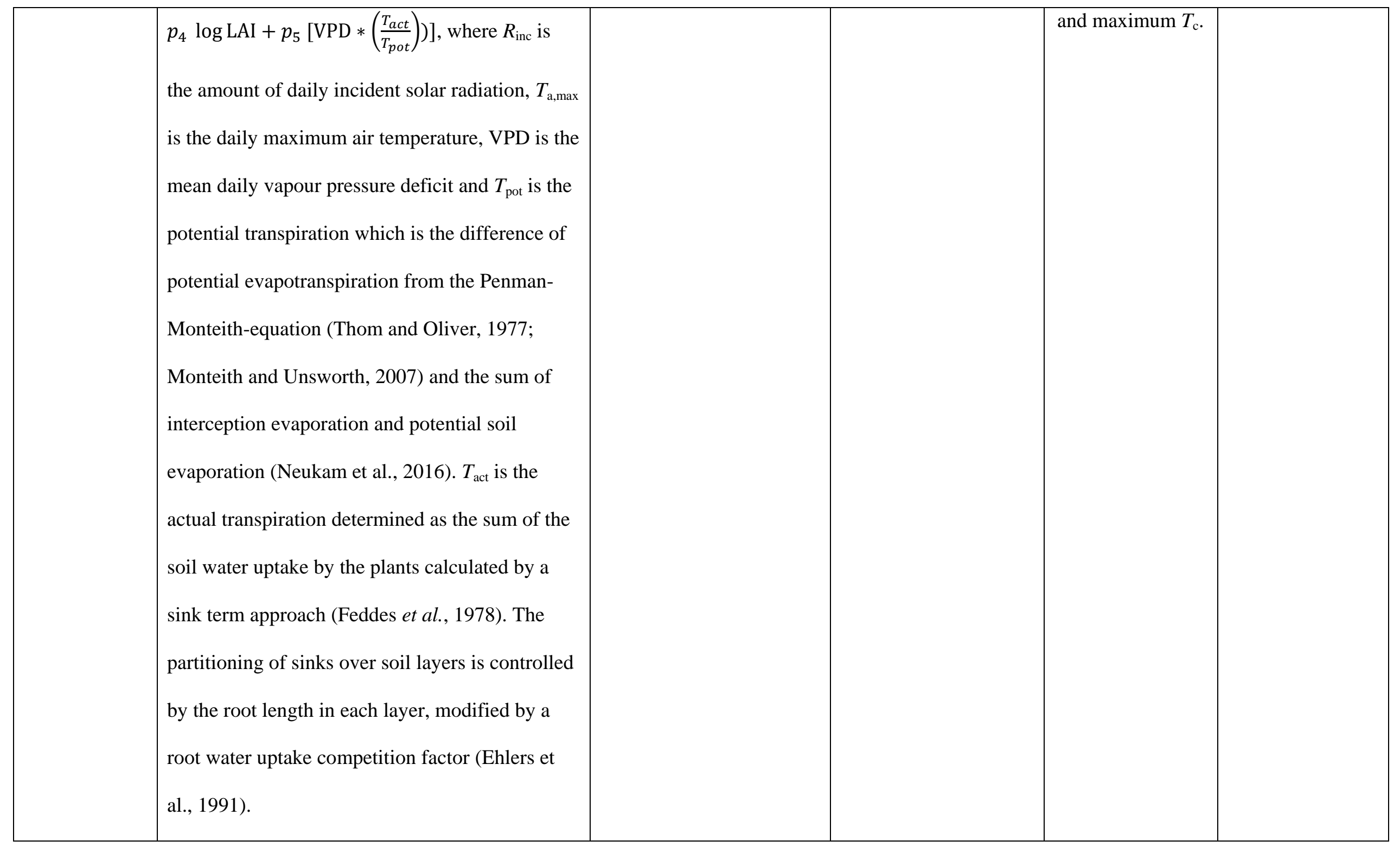




\begin{tabular}{|c|c|c|c|c|c|}
\hline Nwheat (DN, & EMP & $\Delta T$ is related to the actual & Low $\mathrm{N}$ which reduces & $\mathrm{CO}_{2}$ increases & No calibration \\
\hline Asseng et al., & $T_{\mathrm{c}}$ is taken as $6^{\circ} \mathrm{C}$ higher than $T_{\text {air }}$ when the crop & and potential & crop growth also & TE. Less & \\
\hline 1998; Keating & is fully stressed and $6{ }^{\circ} \mathrm{C}^{\mathrm{a}}$ cooler than $T_{\text {air }}$ on & evapotranspiration and & reduces water use and & transpiration & \\
\hline et al., 2003; & average when the crop is fully transpiring & VPD of the atmosphere & therefore $T_{c}$. Under & from increased & \\
\hline Asseng et al., & (Ayeneh et al., 2002; Maes and Steppe, 2012; & (Jackson et al. 1981). & low $\mathrm{N}$, saved water & TE increases $T_{c}$. & \\
\hline \multirow[t]{6}{*}{ 2011) } & Siebert et al., 2014). Between these limits, the & Water stress increases the & later in the season can & Water saved for & \\
\hline & basis of the expression for $T_{\mathrm{c}}$ is the relationship & canopy temperature and & result in more & later in the season & \\
\hline & between $T_{\mathrm{c}}-T_{\text {air }}(\Delta T)$ and the ratio of actual and & accelerates leaf & transpiration later in & can increase late- & \\
\hline & potential evapotranspiration and vapor pressure & senescence. & season and lower $T_{c}$. & season & \\
\hline & deficit (Idso et al., 1981; Jackson et al., 1981) & & & transpiration and & \\
\hline & & & & reduce $T_{c}$. & \\
\hline FASSET (FA; & EMP & Water stress affects & $\mathrm{N}$ affects leaf area & Transpiration is & No calibration \\
\hline Olesen et al., & Based on an empirical relationship between & transpiration directly and & which influences & reduced with & \\
\hline 2002; Doltra & midday crop temperature, evapotranspiration and & indirectly through & transpiration and thus & higher $\mathrm{CO}_{2}$ & \\
\hline et al., 2014; & net radiation (Seguin and Itier, 1983). Maximum & accelerated senescence, & the radiative balance & affecting the & \\
\hline Doltra et al., & and minimum $T_{\mathrm{c}}$ are calculated on a daily time & and the changed & & radiative balance & \\
\hline
\end{tabular}

${ }^{a}$ NWHEAT for this study was implement in a not yet released version of DSSAT 


\begin{tabular}{|c|c|c|c|c|c|}
\hline 2015) & step & $\begin{array}{l}\text { transpiration affects the } \\
\text { radiative balance }\end{array}$ & & $\begin{array}{l}\text { (Doltra et al., } \\
\text { 2014) }\end{array}$ & \\
\hline $\begin{array}{l}\text { Hermes (HE, } \\
\text { (Kersebaum, } \\
\text { 2011; } \\
\text { Kersebaum } \\
\text { and Nendel, } \\
\text { 2014) }\end{array}$ & $\begin{array}{l}\text { EBN } \\
T_{c} \text { is calculated from a hourly energy balance by } \\
\text { summing incident solar radiation, latent and } \\
\text { sensible (H) heat fluxes and solving } T_{c} \text { from } \mathrm{H} \text {. } \\
\text { Hourly temperature and radiation values are } \\
\text { determined following Hoogenboom } \& \text { Huck } \\
(1986) . \text { The sensible heat flux is given by: } \\
H=\frac{\rho c_{P}\left(T_{c}-T_{a}\right)}{r_{a}}, \text { where } \rho \text { is air density, } \mathrm{c}_{\mathrm{p}} \text { the } \\
\text { specific heat of air, } \mathrm{T}_{\mathrm{a}} \text { is air temperature and } \mathrm{r}_{\mathrm{a}} \text { is } \\
\text { the aerodynamic resistance which is calculated } \\
\text { according to Thom and Oliver }(1977) \text { as } \mathrm{r}_{\mathrm{a}}= \\
{\left[4.72\left[\ln \left(\left(\mathrm{z}-\mathrm{d}+\mathrm{z}_{\mathrm{o}}\right) / \mathrm{z}_{\mathrm{o}}\right)\right]^{2}\right] /(1+0.54 \mathrm{u}) \text { where } \mathrm{u}} \\
\text { is wind speed at reference height } \mathrm{z}, \mathrm{d} \text { the zero- } \\
\text { displacement height equal } 1.04 \mathrm{~h}^{0.88} \text { and } \mathrm{z}_{\mathrm{o}} \text { the } \\
\text { roughness length for momentum and heat } \\
\text { transfer each equal to } \mathrm{z}_{0}=0.062 \mathrm{~h}^{1.08}, \text { where } \mathrm{h} \text { is }\end{array}$ & $\begin{array}{l}\text { Cooling effect of } \\
\text { evapotranspiration is } \\
\text { considered in the energy } \\
\text { balance. Consequently } \\
\text { limited water reduces } \\
\text { cooling and resulting } \\
\text { higher } T_{c} \text { accelerates } \\
\text { phenological } \\
\text { development. }\end{array}$ & $\begin{array}{l}\text { Limited N may } \\
\text { reduce LAI for light } \\
\text { interception of the } \\
\text { canopy, but also } \\
\text { transpiration. N stress } \\
\text { accelerates } \\
\text { phenological } \\
\text { development }\end{array}$ & $\begin{array}{l}\text { Stomatal } \\
\text { resistance is } \\
\text { modified by } \mathrm{CO}_{2} \text {. } \\
\text { (Kersebaum and } \\
\text { Nendel, 2014). } \\
\text { Therefore, } \\
\text { elevated } \mathrm{CO}_{2} \\
\text { slightly increase } \\
\text { Tc through } \\
\text { reduced } \\
\text { transpiration and } \\
\text { higher LAI }\end{array}$ & No calibration \\
\hline
\end{tabular}




\begin{tabular}{|c|c|c|c|c|c|}
\hline & $\begin{array}{l}\text { the crop height. In the hourly energy balance, } \\
\text { with the Penman-Monteith } \mathrm{ET}_{0} \text { equation and } \\
\text { crop coefficient (Allen et al., 1998) where the } \\
\text { stomatal resistance term is adjusted to consider } \\
\text { ambient } \mathrm{CO}_{2} \text { levels (Kersebaum and Nendel, } \\
\text { 2014). }\end{array}$ & & & & \\
\hline $\begin{array}{l}\text { SiriusQuality } \\
\text { (SQ; Martre et } \\
\text { al., 2006; } \\
\text { http://www1.c } \\
\text { lermont.inra.fr } \\
\text { /siriusquality/; } \\
\text { Maiorano et } \\
\text { al., 2017) }\end{array}$ & $\begin{array}{l}\text { EBN } \\
T_{\mathrm{c}} \text { is calculated from a daily energy balance by } \\
\text { summing incident solar radiation, soil, latent and } \\
\text { sensible }(H) \text { heat fluxes and solving } T_{\mathrm{c}} \text { from } H \\
\text { (Jamieson et al., 1995). The sensible heat flux is } \\
\text { given by: } H=\frac{\rho c_{P}\left(T_{c}-T_{a}\right)}{r_{a}} \text {, where } \rho \text { is air density, } \\
c_{\mathrm{p}} \text { the specific heat of air, } T_{\mathrm{a}} \text { is air temperature } \\
\text { and } r_{\mathrm{a}} \text { is the aerodynamic resistance which is } \\
\text { calculated assuming neutral stability conditions } \\
\text { according to Monteith (1973) as: } r_{\mathrm{a}}=k^{2} u /[\ln [(z- \\
\left.\left.d) / z_{\mathrm{o}}\right]\right]^{2} \text { with } k \text { the von Karmin constant equal to } \\
0.40, u \text { the wind speed at reference height } z, d \text { the }\end{array}$ & $\begin{array}{l}\text { Indirectly through } \\
\text { reduced transpiration and } \\
\text { accelerated canopy } \\
\text { senescence. }\end{array}$ & $\begin{array}{l}\text { Indirectly through } \\
\text { reduced LAI under } \\
\text { low Nconditions. }\end{array}$ & $\begin{array}{l}\text { No direct } \\
\text { feedbacks of } \\
\mathrm{CO}_{2} .\end{array}$ & No calibration \\
\hline
\end{tabular}




\begin{tabular}{|c|c|c|c|c|c|}
\hline & $\begin{array}{l}\text { zero-displacement height equal to } 0.13 \times h \text { and } z_{\mathrm{o}} \\
\text { the roughness length for momentum and heat } \\
\text { transfer each equal to } 0.63 \times h \text {, where } h \text { is the } \\
\text { crop height. }\end{array}$ & & & & \\
\hline $\begin{array}{l}\text { SSM-Wheat } \\
\text { (SS, Soltani et } \\
\text { al., 2013) }\end{array}$ & $\begin{array}{l}\text { EBN } \\
T_{\mathrm{c}} \text { is calculated from a daily energy balance by } \\
\text { summing incident solar radiation, soil, latent and } \\
\text { sensible ( } H \text { ) heat fluxes and solving } T_{\mathrm{c}} \text { from } H \text {. } \\
\text { The sensible heat flux is given by: } H= \\
\frac{\rho c_{P}\left(T_{c}-T_{a}\right)}{r_{a}} \text {, where } \rho \text { is air density, } c_{\mathrm{p}} \text { the specific } \\
\text { heat of air, } T_{\mathrm{a}} \text { is air temperature and } r_{\mathrm{a}} \text { is the } \\
\text { aerodynamic resistance which is calculated } \\
\text { assuming neutral stability conditions according to } \\
\text { Monteith (1973) as: } r_{\mathrm{a}}=k^{2} u /\left[\ln \left[(z-d) / z_{\mathrm{o}}\right]\right]^{2} \text { with } \\
k \text { the von Karmin constant equal to } 0.40, u \text { the } \\
\text { wind speed at reference height } z, d \text { the zero- } \\
\text { displacement height equal to } 0.13 \times h \text { and } z_{\mathrm{o}} \text { the } \\
\text { roughness length for momentum and heat }\end{array}$ & $\begin{array}{l}\text { Indirect. Water stress } \\
\text { affects (reduces) the daily } \\
\text { accumulation of biomass } \\
\text { and LAI, thus modifying } \\
\text { the evaporation from soil } \\
\text { and the transpiration. } \\
\text { These, in turn, affect the } \\
\text { energy balance. }\end{array}$ & $\begin{array}{l}\text { Indirect. Daily LAI } \\
\text { formation, and in turn } \\
\text { biomass } \\
\text { accumulation, is } \\
\text { regulated by nitrogen } \\
\text { availability, thus } \\
\text { affecting daily } \\
\text { evapotranspiration } \\
\text { and, in turn, the } \\
\text { energy balance. }\end{array}$ & $\begin{array}{l}\text { Indirect. } \mathrm{CO}_{2} \\
\text { affects daily } \\
\text { biomass } \\
\text { accumulation } \\
\text { through } \\
\text { modifying the } \\
\text { radiation use } \\
\text { efficiency and } \\
\text { the transpiration } \\
\text { efficiency. } \\
\text { Evapotranspirati } \\
\text { on may vary } \\
\text { accordingly, thus } \\
\text { affecting the }\end{array}$ & No calibration \\
\hline
\end{tabular}




\begin{tabular}{|c|c|c|c|c|c|}
\hline & $\begin{array}{l}\text { transfer each equal to } 0.63 \times h \text {, where } \mathrm{h} \text { is the } \\
\text { crop height (Jamieson et al., 1995). }\end{array}$ & & & energy balance. & \\
\hline $\begin{array}{l}\text { Sirius2014 } \\
\text { (S2; Jamieson } \\
\text { et al., 1998; } \\
\text { Jamieson and } \\
\text { Semenov, } \\
\text { 2000; Lawless } \\
\text { et al., 2005) }\end{array}$ & $\begin{array}{l}\text { EBN } \\
T_{\mathrm{c}} \text { is calculated from a daily energy balance by } \\
\text { summing incident solar radiation, soil, latent and } \\
\text { sensible }(H) \text { heat fluxes and solving } T_{\mathrm{c}} \text { from } H \\
\text { (Jamieson et al., 1995). The sensible heat flux is } \\
\text { given by: } H=\frac{\rho c_{P}\left(T_{c}-T_{a}\right)}{r_{a}}, \text { where } \rho \text { is air density, } \\
c_{\mathrm{p}} \text { the specific heat of air, } T_{\mathrm{a}} \text { is air temperature } \\
\text { and } r_{\mathrm{a}} \text { is the aerodynamic resistance which is } \\
\text { calculated assuming neutral stability conditions } \\
\text { according to Monteith (1973) as: } r_{\mathrm{a}}=k^{2} u / \text { [ln[ }[(z- \\
\left.\left.d) / z_{\mathrm{o}}\right]\right]^{2} \text { with } k \text { the von Karmin constant equal to } \\
0.40, u \text { the wind speed at reference height } z, d \text { the } \\
\text { zero-displacement height equal to } 0.13 \times h \text { and } z_{\mathrm{o}} \\
\text { the roughness length for momentum and heat } \\
\text { transfer each equal to } 0.63 \times h \text {, where } h \text { is the } \\
\text { crop height. }\end{array}$ & $\begin{array}{l}T_{\mathrm{c}} \text { is affected by } \\
\text { increased water stress } \\
\text { which causes } \\
\text { transpiration to decrease } \\
\text { altering the energy } \\
\text { balance (Jamieson et al., } \\
\text { 1995) }\end{array}$ & $\begin{array}{l}\text { No direct feedbacks } \\
\text { of N. However, } \mathrm{N} \\
\text { affects canopy growth } \\
\text { and, potentially, } \\
\text { dynamics of } T_{\mathrm{c}} \\
\text { (Lawless et al., 2005) }\end{array}$ & $\begin{array}{l}\text { No direct } \\
\text { feedbacks of } \\
\mathrm{CO}_{2} \text {. However, } \\
\mathrm{CO}_{2} \text { affects } \\
\text { canopy growth } \\
\text { and, potentially, } \\
\text { dynamics of } T_{\mathrm{c}} \\
\text { (Lawless et al., } \\
\text { 2005) }\end{array}$ & No calibration \\
\hline
\end{tabular}




\begin{tabular}{|c|c|c|c|c|c|}
\hline $\begin{array}{l}\text { SIMPLACE< } \\
\text { Lintul2 >* } \\
\text { (SP; Gaiser et } \\
\text { al., 2013) }\end{array}$ & $\begin{array}{l}\text { EBSC } \\
T_{c} \text { is calculated from an hourly energy balance } \\
\text { by summing incident solar radiation, soil, latent } \\
\text { and sensible }(H) \text { heat fluxes and solving } T_{\mathrm{c}} \text { from } \\
H . \text { Atmospheric stability is considered by using } \\
\text { Monin-Obukhov Similarity Theory (MOST) and } \\
\text { empirical stability correction factors to solve for } \\
r_{\mathrm{a} \cdot} T_{\mathrm{c}} \text { is calculated for two bounding extremes: } \\
\text { upper (no transpiration) and lower (full } \\
\text { transpiration) limits of } T_{\mathrm{c}} \text {, avoiding the need to } \\
\text { specify canopy resistance terms at intermediate } \\
\text { transpiration rates. With these two extreme } \\
\text { potential values of } T_{c}, \text { actual } T_{\mathrm{c}}=T_{\mathrm{c}, \mathrm{L}}+ \\
\left(1-K_{\mathrm{WS}}\right)\left(T_{\mathrm{c}, \mathrm{U}}-T_{\mathrm{c}, \mathrm{L}}\right) \text { where } K_{\mathrm{ws}} \text { is soil water } \\
\text { stress index. A full description is given in } \\
\text { Webber et al. ( } 2016 \mathrm{~b} \text { ). }\end{array}$ & $\begin{array}{l}\text { Soil water stress index is } \\
\text { used to determine } T_{\mathrm{c}} \\
\text { between the upper (no } \\
\text { transpiration) and lower } \\
\text { (full transpiration) limit } \\
\text { of } T_{\mathrm{c}} \text {. The rate of } \\
\text { transpiration also } \\
\text { influences the energy } \\
\text { balance of each limit as } \\
\text { well as the stability } \\
\text { correction terms. }\end{array}$ & No-feedback & $\begin{array}{l}\text { No effect of } \mathrm{CO}_{2} \\
\text { on hourly } \\
\text { transpiration or } \\
T_{\mathrm{c}} \text {, However, } \\
\text { daily } \\
\text { transpiration is } \\
\text { reduced using an } \\
\text { empirical } \\
\text { reduction } \\
\text { function in } \\
\text { response to } \\
\text { elevated } \mathrm{CO}_{2} \text { and } \\
\text { this affects soil } \\
\text { water content } \\
\text { which has an } \\
\text { effect on } T_{\mathrm{c}} \text {. }\end{array}$ & $\begin{array}{l}\text { Varietal canopy } \\
\text { resistance term } \\
\text { and terms that } \\
\text { control wind } \\
\text { speed due to } \\
\text { assumptions of } \\
\text { height of } \\
\text { surrounding } \\
\text { vegetation }\end{array}$ \\
\hline $\begin{array}{l}\text { SIMPLACE< } \\
\text { Lintul5>** }\end{array}$ & $\begin{array}{l}\text { EBSC } \\
T_{\mathrm{c}} \text { is calculated from an hourly energy balance }\end{array}$ & $\begin{array}{l}\text { Soil water stress index } \\
\text { used to determine } T_{\mathrm{c}}\end{array}$ & $\begin{array}{l}\text { Indirect. Daily LAI } \\
\text { formation, and in turn }\end{array}$ & $\begin{array}{l}\text { Direct. Linear } \\
\text { function }\end{array}$ & $\begin{array}{l}\text { Varietal canopy } \\
\text { resistance term }\end{array}$ \\
\hline
\end{tabular}




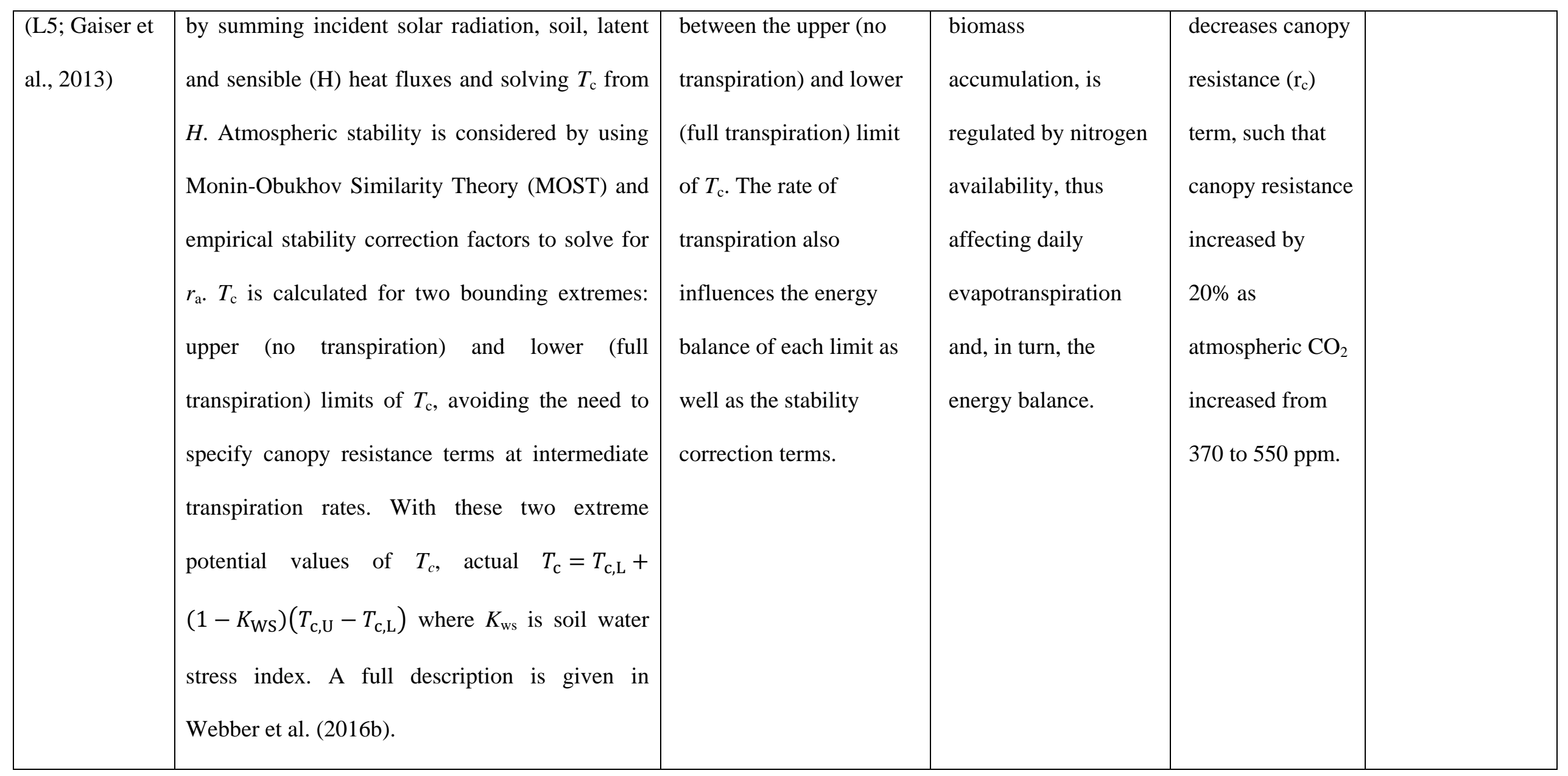

* SIMPLACE $<$ Lintul2 $>$ is the shortened name for SIMPLACE $<$ Lintul2,CC,DailyHeat,CanopyT $>$.

** SIMPLACE<Lintul5> is the shortened name for SIMPLACE<Lintul5,FAO-56,HourlyHeat,CanopyT>. 


\section{Model evaluation}

Three measures of model performance were considered. The square root (RMSE) of the mean squared error and the coefficient of determination $\left(R^{2}\right)$ were determined for $\Delta T$, grouped across similar nitrogen and $\mathrm{CO}_{2}$ levels, across years in the FACE-Maricopa experiment and grouped across water treatments, years and sites (five China Wheat experiments plus FACE-Maricopa). The RMSE was calculated as:

$$
\operatorname{RMSE}=\sqrt{\frac{1}{N} \sum_{i=1}^{N}\left(\Delta T_{S, i}-\Delta T_{o, i}\right)^{2}}
$$

where $\Delta T_{\mathrm{o}, \mathrm{i}}$ is the $i$ th observation of $\Delta T, \Delta T_{s, i}$ is the $i$ th simulated $\Delta T$ value, and $N$ is the total number of observation and simulation pairs. Observations and simulations for a particular treatment were pooled across dates and years for the FACE-Maricopa experiment, and across dates, years and sites for the China Wheat experiment.

Analyses of variance for multivariate linear regressions were conducted using PROC GLM in the SAS statistical software (version 9.4, SAS Institute; Cary, NC). Sequential sums of squares (Type I) were used to quantify the variation described by a factor, given any variation attributable to variables previously included in the linear model. Given the importance of how the variables were ordered, various sequences were explored. Typically, variables were introduced sequentially based on their explaining progressively less variation or based on their relevance for testing specific hypotheses relating to comparisons of observed vs. simulated data.

For the FACE data, four basic linear models were considered. The first used year, treatment and finally weather to characterize variation in observed $\Delta T$. In the second group of tests, daily weather variables were tested first, followed by treatment effects to explain variation in observed $\Delta T$. These analyses helped characterize how treatments and environmental variables drove variability in observed $\Delta T$. In the third model, simulated $\Delta T$, followed by year and treatment effects were considered to determine how well the 
simulated $\Delta T$ explained variation in the observations, as well as assess how much variation remained due to years and the treatments not explained by a given crop model. In the final group of tests, VPD at $T_{\max }$ $\left(\mathrm{VPD}_{\mathrm{Tmax}}\right)$, followed by the simulated $\Delta T$ and then the treatment factors were used to assess how much variation in observed $\Delta T$ a model could explain beyond that of the expected, large VPD effect. The linear models tested for the China Wheat data were similar but differed in that site was the highest level of the hierarchy. Given evidence that ensembles of crop models often out-perform any individual model (Martre et al., 2015), two multi-model ensembles were created from the mean (e.mean) and the median (e.median). The reference HU model was excluded from the ensemble analyses.

To explicitly evaluate if the performance of the EBSC models was infact related to stability considitons and not another confounding factor, we estimated the stability conditions of the boundary layer for each observation of $T_{c}$ using the formulation of Richards' number $(R i)$ as reported in Mahrt and Ek (1983) as:

$$
R i=\frac{g\left(T_{a}-T_{c}\right) z}{T_{a} u^{2}}
$$

Where $\mathrm{g}$ is the acceleration due to gravity in $\mathrm{ms}^{-2}, \mathrm{z}$ is the height that atmospheric measurement observed at in $\mathrm{m}$, and $\mathrm{u}$ is the wind speed in $\mathrm{ms}^{-1}$.

\section{Results}

\section{Canopy temperature and canopy temperature depression observations and simulations}

There was considerable intra- and inter-annual variation in daily maximum air temperature $\left(T_{\max }\right)$ for the FACE-Maricopa experiment (Fig. 2a to 2d) and additionally, among sites for the China Wheat experiment (Figs. 3a to 3d and 4a to $4 \mathrm{~d}$ ), with observed $T_{c}$ largely following $T_{\max }$. In the FACE-Maricopa experiment, observed $\Delta T$ in the fully irrigated conditions tended to be negative, whereas under semi-irrigated conditions observed $\Delta T$ was less negative and frequently positive in 1993 (Fig. 2a and 2b). Similarly, in 
the China Wheat experiment, $\Delta T$ tended to be negative indicating canopy cooling in the irrigated treatments (Fig. 3f to 3j, and Fig. 4e to 4h) except at Tryon, NE (site NESA) which had sandy soil and the measured $\Delta T$ values suggest frequent water deficits even under irrigation. The effect of elevated $\mathrm{CO}_{2}$ and nitrogen status were more subtle (Fig. $2 \mathrm{e}$ to $2 \mathrm{~h}$ ) though $\Delta T$ tended to be less negative under elevated $\mathrm{CO}_{2}$, and with low nitrogen levels. As reported in Kimball et al. (1999), elevated $\mathrm{CO}_{2}$ raised $T_{c}$ by $0.6^{\circ} \mathrm{C}$ and $1.1^{\circ} \mathrm{C}$ compared to ambient $\mathrm{CO}_{2}$ concentrations at high and low nitrogen levels, respectively. These results are consistent with decreases in stomatal conductance and similar increases in $T_{c}$ observed on leaves in cuvettes obtained with portable photosynthesis systems (Wall et al., 2000; Wall et al., 2006).

With few exceptions, observed variation in $\Delta T$ in the FACE-Maricopa experiment was captured by at least one model in the ensemble, as indicated by the grey banding of Figure $2 \mathrm{e}$ to $2 \mathrm{~h}$, though individual models differed widely (Fig. S2 and Tables 2 and 3). The multi-model ensemble median (e.median) correlations across the various nitrogen and $\mathrm{CO}_{2}$ treatments are presented in Table 2. The EBSC models consistently had the highest $R^{2}$ and lowest RMSE values while the reference model HU in most cases had better performance in these well-watered treatments. The e.median estimator failed to capture the differences between 1993 and 1994 in which 1993 had positive $\Delta T$ values for the semi-irrigated treatment, whereas observations in 1994 had large negative $\Delta T$ in both the full- and semi-irrigated treatments. Likewise, the reference model $\mathrm{HU}$ calibrated to the ambient $\mathrm{CO}_{2}$ data for these treatments had a $R^{2}$ of only 0.22 . In the China Wheat experiment, there were relatively more instances where observed $\Delta T$ was outside of the range of simulated $\Delta T$ (Figs. 3 and 4, Fig. S3). When data were pooled across all sites of the China Wheat experiment, e.median had $R^{2}$ values of 0.41 and $0.26(P<0.05)$ for the irrigated and rainfed treatments, respectively, except from the HU model which was independently parametrized from this data. The EBSC models had the best agreement with observations. The EMP models generally performed better than the EBN models. However, it is hard to generalize across the EBN models, as the performance of individual models varied with treatment and $R^{2}$ values sometimes had insignificant or near zero correlations with observations. 

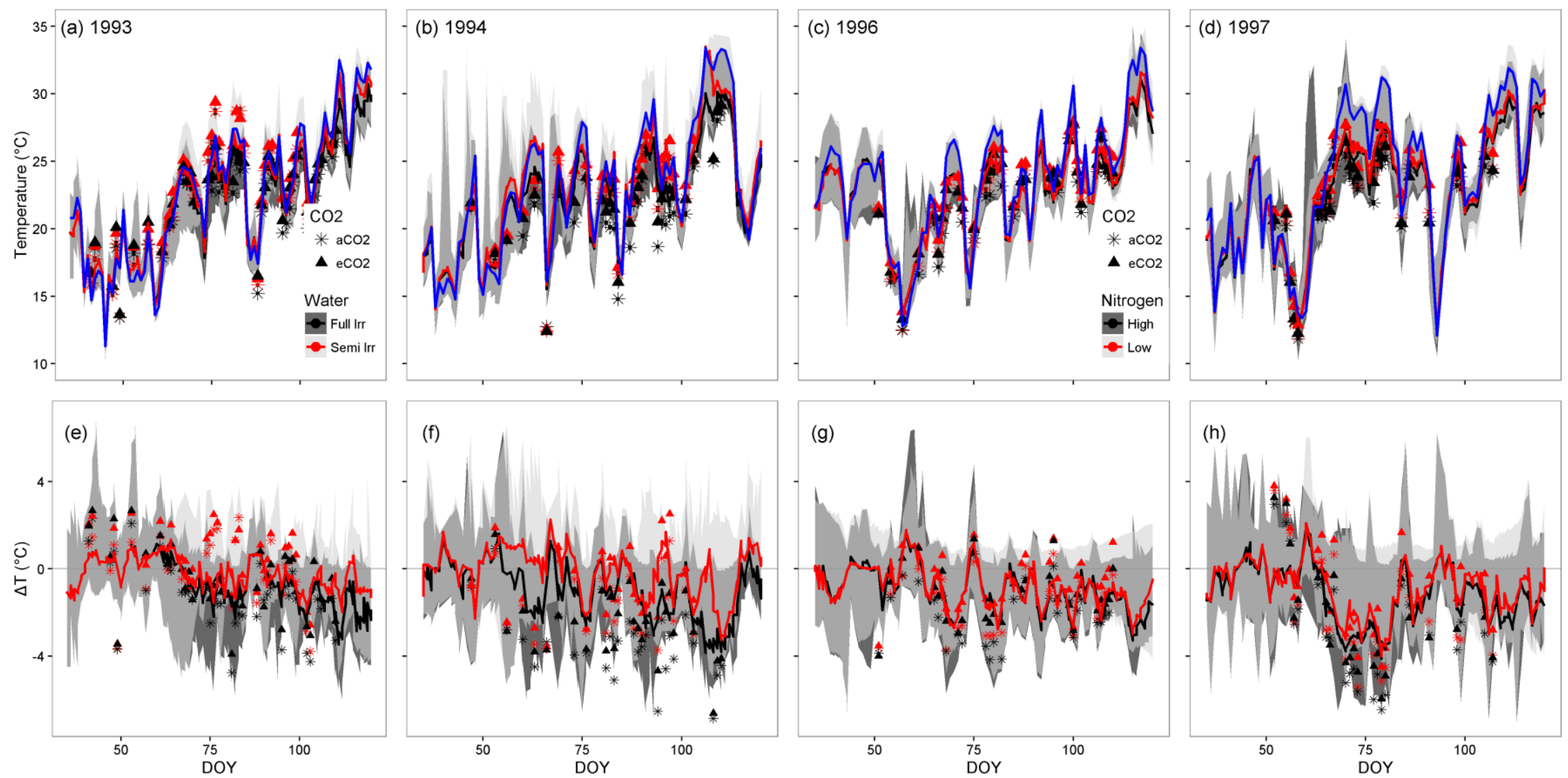

Figure 2. Time course of observed daily maximum air temperature ( $T_{\max }$, blue line), mid-day canopy temperature $\left(T_{\mathrm{c}}\right)$ observations (symbols) and the range (shaded areas) and median (red and black lines) values of simulated daily maximum $T_{\mathrm{c}}$ across models for the FACE-Maricopa experiment in (a) 1993, (b) 1994, (c) 1996, and (d) 1997. The differences between $T_{c}$ and $T_{\max }\left(\Delta T=T_{c}-T_{\max }\right.$ ) are presented for the (e) 1993, (f) 1994, (g) 1996, and (h) 1997 harvest years. In all panels, star symbols are ambient $\mathrm{CO}_{2}$ and triangles are elevated $\mathrm{CO}_{2}$. In (a), (b), (e), and (f) the black symbols are full irrigation, red symbols are semi irrigated, the dark grey banding is full irrigation, light grey is semi irrigated, their 
intersection is medium grey, and black and red lines are median values of model simulations for full irrigation and semi irrigated, respectively. In (c), (d), (g), and (h) the black symbols are high nitrogen fertilizer rates, red symbols are low nitrogen fertilizer rates, the dark grey banding is high nitrogen, light grey is low nitrogen, their intersection is medium grey and black and red lines are median values of model simulations for high and low nitrogen, respectively. Observations of $T_{\mathrm{c}}$ and $\Delta T$ are only shown when the canopy was near fully closed.

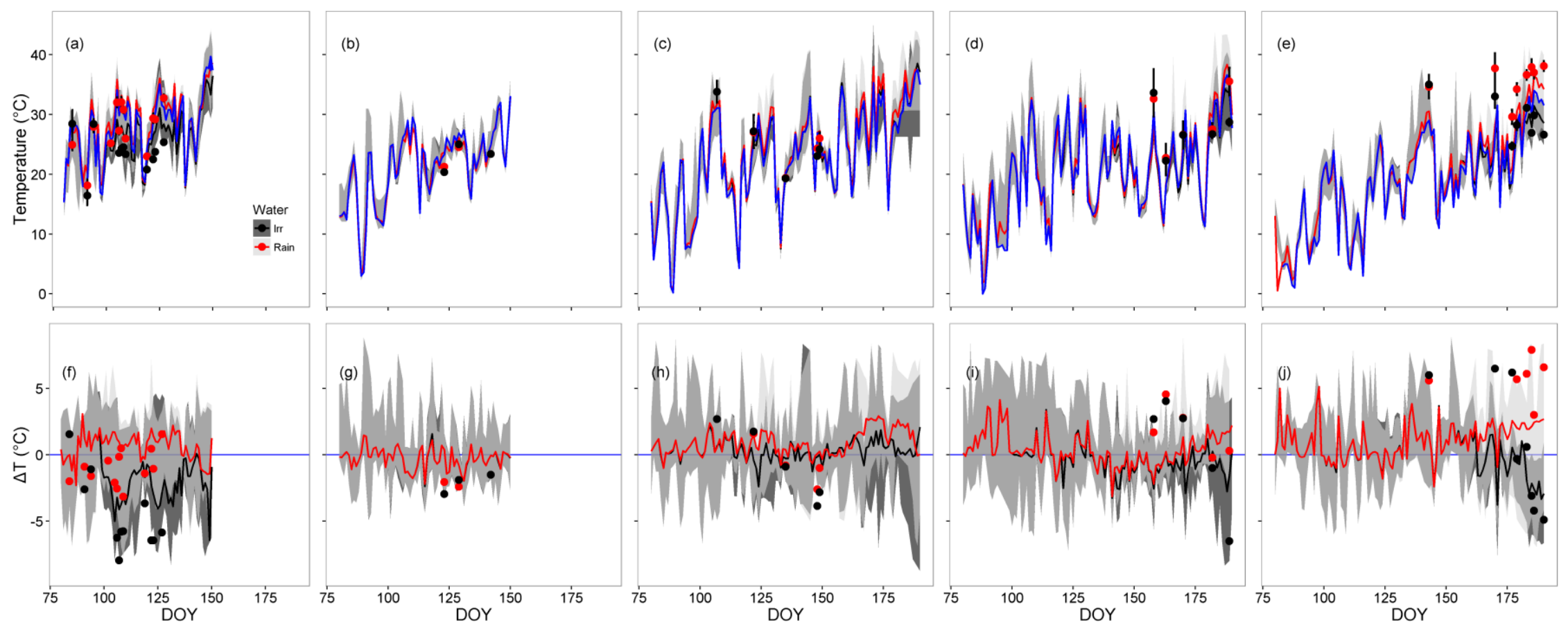

Figure 3. Time course of observed daily maximum air temperature ( $T_{\max }$, blue lines), mid-day canopy temperature $\left(T_{\mathrm{c}}\right)$ observations (symbols) and the range (shaded areas) and median (red and black lines) values of simulated daily maximum $T_{\mathrm{c}}$ across models for the China Wheat experiment in 1985 at (a) Lubbock, TX, (b) Manhattan, KS, (c) Tryon, NE, (d) Mandan, ND and (e) Lethbridge, AB. The differences between $T_{\mathrm{c}}$ and $T_{\text {air }}(\Delta T=$ 
$T_{\mathrm{c}}-T_{\max }$ ) are presented for (f) Lubbock, TX, (g) Manhattan, KS, (h) Tryon, NE, (i) Mandan, ND and (j) Lethbridge, AB. The black symbols are full irrigation, red symbols are semi irrigated, the dark grey banding is full irrigation, light grey is semi irrigated, their intersection is medium grey, and black and red lines are median values of model simulations for full irrigation and semi irrigated, respectively. Observations of $T_{\mathrm{c}}$ and $\Delta T$ are only shown when the canopy was near fully closed.

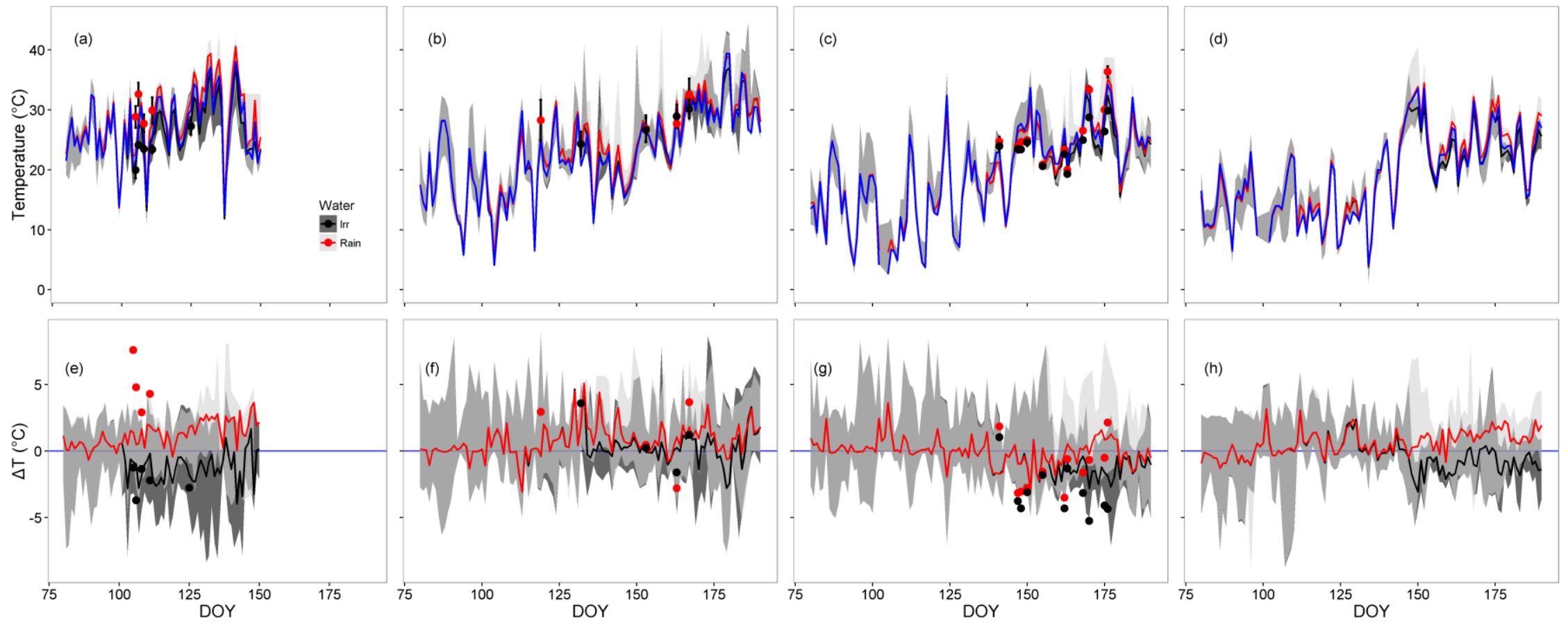

Figure 4. Time course of observed daily maximum air temperature ( $T_{\text {air }}$, blue line), mid-day canopy temperature $\left(T_{\mathrm{c}}\right)$ observations (symbols) and the range (shaded areas and median (red and black lines) values of simulated daily maximum $T_{\mathrm{c}}$ values across models for China Wheat experiment 
in 1986 at (a) Lubbock, TX, (b) Tryon, NE, (c) Mandan, ND and (d) Lethbridge, AB. The difference between $T_{\mathrm{c}}$ and $T_{\text {air }}\left(\Delta T=T_{\mathrm{c}}-T_{\text {air }}\right)$ are presented in (e) Lubbock, TX, (f) Tryon, NE, (g) Mandan, ND and (h) Lethbridge, AB. The black symbols are full irrigation, red symbols are semi irrigated, the dark grey banding is full irrigation, light grey is semi irrigated, their intersection is medium grey, and black and red lines are median values of model simulations for full irrigation and semi irrigated, respectively. Observations of $T_{\mathrm{c}}$ and $\Delta T$ are only shown when the canopy was near fully closed. 
Table 2. Coefficient of determination $\left(R^{2}\right)$ of observed vs. simulated $\Delta T\left(\Delta T=T_{c}-T_{\text {air }}\right)$ across production conditions and water, nitrogen, and $\mathrm{CO}_{2}$ factors by experiment. The values for water supply treatments (Irr - irrigated and Rain - rainfed) for the China Wheat (CW) experiment consider data pooled across sites and years. Data from the FACE-Maricopa experiment are pooled across years for all treatments. Only $R^{2}$ values that were statistically significant at $P=0.05$ are reported.

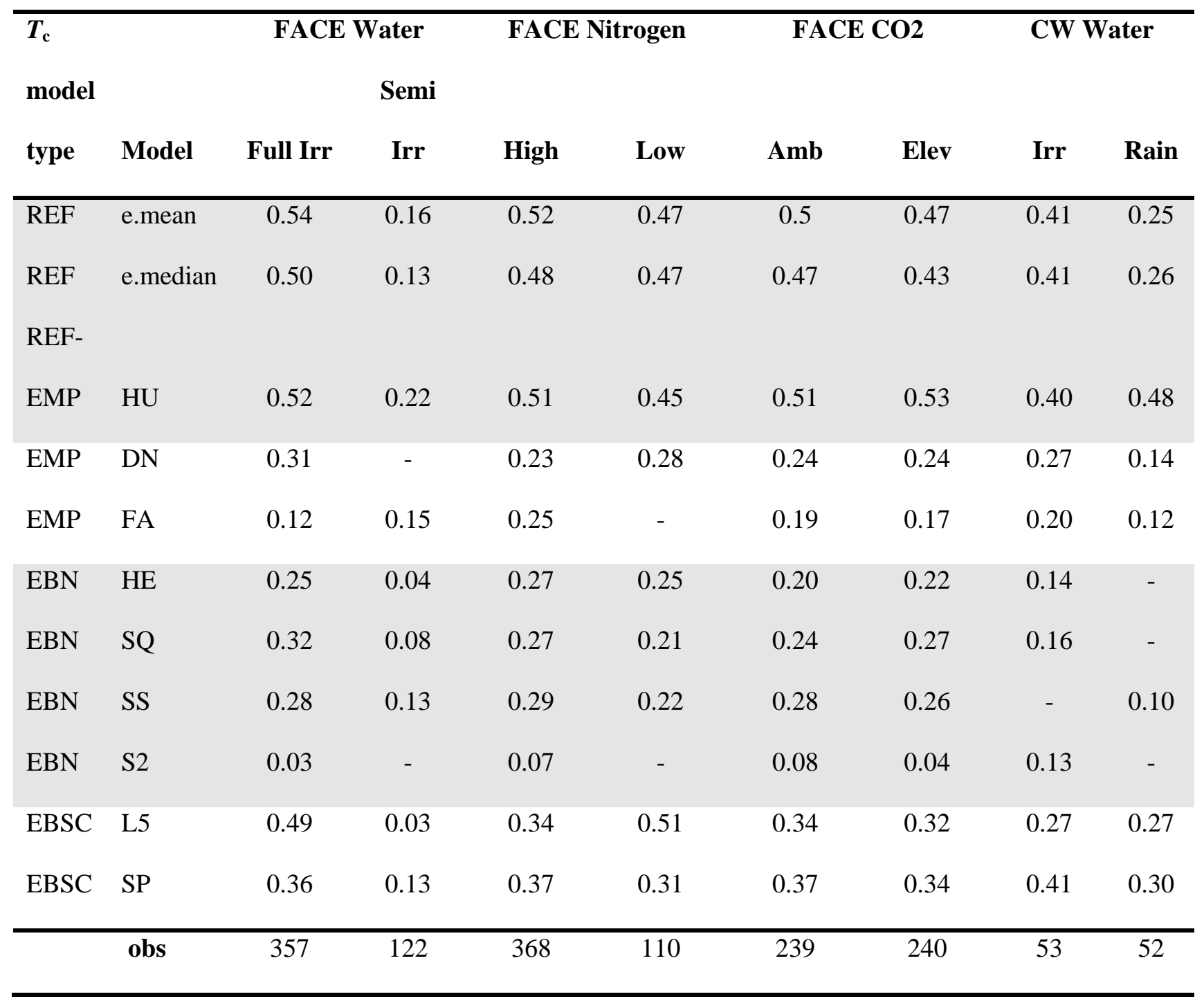

Table 3. Root mean square error (RMSE) of $\Delta T\left(\Delta T=T_{c}-T_{a i r}\right)$ across production conditions and water, nitrogen, and $\mathrm{CO}_{2}$ factors by experiment. The values for water supply treatments (Irr-irrigated and Rain- 
rainfed) for the China Wheat $(\mathrm{CW})$ experiment considered data pooled across sites and years. Data from the FACE-Maricopa experiment were pooled across years for all treatments.

\begin{tabular}{|c|c|c|c|c|c|c|c|c|c|}
\hline \multirow{3}{*}{$\begin{array}{c}T_{\mathrm{c}} \\
\text { model } \\
\text { type }\end{array}$} & \multirow[b]{3}{*}{ Model } & \multicolumn{2}{|c|}{ FACE Water } & \multicolumn{2}{|c|}{ FACE Nitrogen } & \multicolumn{2}{|c|}{ FACE CO2 } & \multicolumn{2}{|c|}{ CW Water } \\
\hline & & Full & Semi & & & & & & \\
\hline & & Irr & Irr & High & Low & Amb & Elev & Irr & Rain \\
\hline REF & e.mean & 1.59 & 1.65 & 1.65 & 1.46 & 1.75 & 1.45 & 2.86 & 3.37 \\
\hline REF & e.median & 1.55 & 1.66 & 1.63 & 1.39 & 1.68 & 1.48 & 2.83 & 3.36 \\
\hline \multicolumn{10}{|l|}{ REF- } \\
\hline EMP & $\mathrm{HU}$ & 1.36 & 1.55 & 1.42 & 1.39 & 1.42 & 1.4 & 2.89 & 3.1 \\
\hline EMP & $\mathrm{DN}$ & 2.07 & 2.76 & 2.37 & 1.87 & 2.09 & 2.42 & 2.91 & 3.66 \\
\hline EMP & FA & 1.87 & 1.85 & 1.77 & 2.17 & 1.76 & 1.97 & 3.33 & 4.3 \\
\hline EBN & $\mathrm{HE}$ & 2.09 & 3.21 & 2.57 & 1.89 & 2.56 & 2.29 & 3.88 & 5.21 \\
\hline EBN & SQ & 2.94 & 2.04 & 2.69 & 2.93 & 3.08 & 2.36 & 3.42 & 5.84 \\
\hline EBN & SS & 2.35 & 1.9 & 2.24 & 2.28 & 2.44 & 2.04 & 5.25 & 3.64 \\
\hline EBN & S2 & 2.92 & 3.1 & 3.11 & 2.45 & 3.21 & 2.71 & 3.94 & 3.97 \\
\hline EBSC & L5 & 1.49 & 2.11 & 1.76 & 1.32 & 1.71 & 1.63 & 3.01 & 3.23 \\
\hline EBSC & SP & 1.59 & 2.05 & 1.75 & 1.6 & 1.83 & 1.61 & 2.67 & 3.39 \\
\hline
\end{tabular}

\section{Decomposing sources of variation in $\Delta T$}

Four types of analysis were used to assess which factors explained the most variation in observed $\Delta T$, including multiple regression models in which various treatments factors (water, $\mathrm{CO}_{2}$, and nitrogen), year effects or weather effects $\left(\mathrm{VPD}_{\mathrm{Tmax}}, \mathrm{ET}_{\mathrm{o}}\right.$, solar radiation) were examined. For the FACE-Maricopa dataset, $\mathrm{VPD}_{\mathrm{Tmax}}$ explained the greatest amount of variation in observed $\Delta T$, explaining $33 \%$ of the variation, with solar radiation explaining an additional 10\% (Fig. 5a). After the weather variables were 
controlled for, treatment effects of $\mathrm{CO}_{2}$, nitrogen and water, tested in that order, explained an additional 5, 2 and 5\%, respectively. The remaining residual variation in the observations was $38 \%$. For the China Wheat experiment, $\mathrm{VPD}_{\mathrm{Tmax}}$ explained only $1 \%$ of variation in observed $\Delta T$ (Fig. 5b), with little additional variation explained by the weather variables assessed next. The greatest amount of variation (28\%) was due to experimental site after weather variables were controlled for. Year effects explained a further $10 \%$ of variation with water treatment explaining $27 \%$ of variation. Readers should be reminded that unlike the FACE-Maricopa experiment in which observations spanned the season over a wide temperature range (Fig. 2), in the China Wheat experiment there were a limited and variable number of observations per year and site (Figs. 3 and 4). For this reason, caution must be taken in interpretation of Fig. 5b, as it represents the drivers of variation in the available observations, not the expected drivers of $\Delta T$ over the entire growing season.

(a)

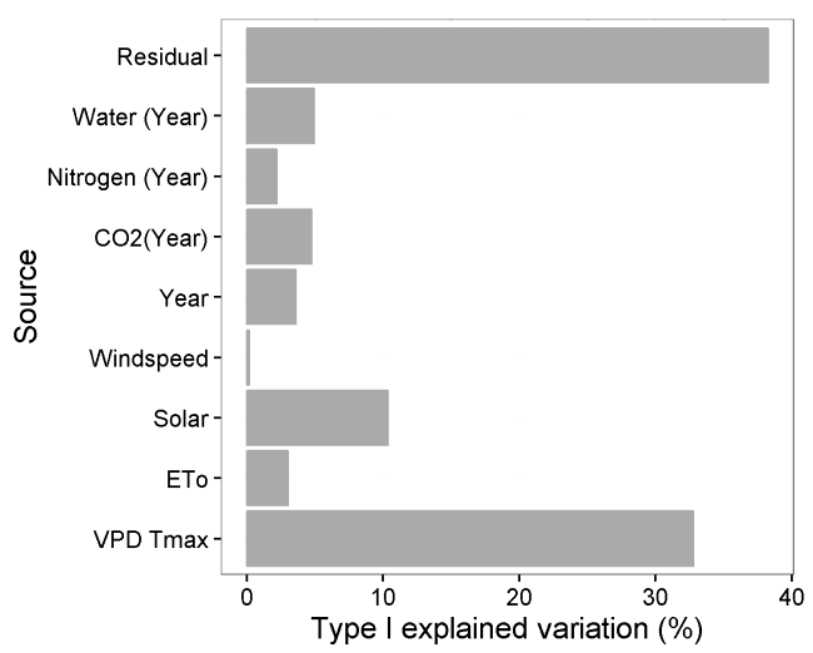

(b)

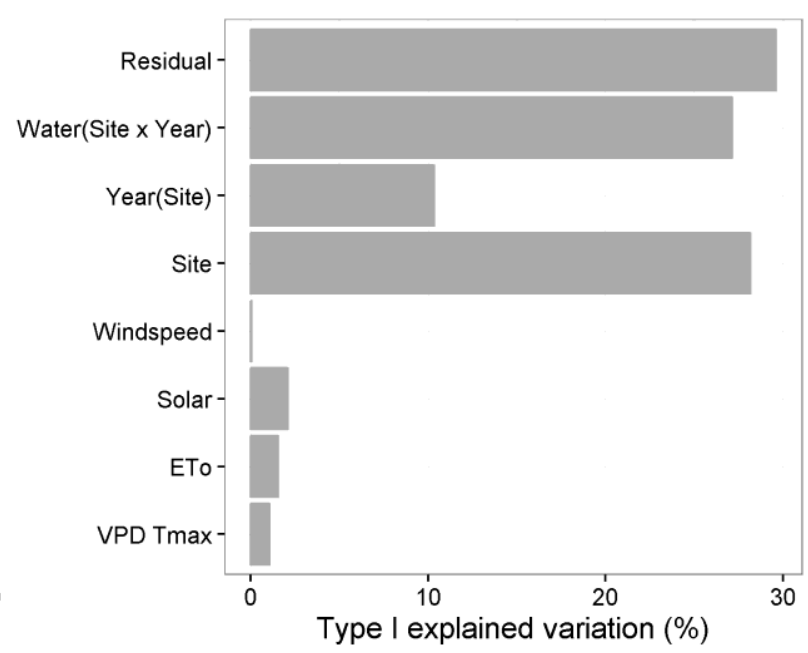

Figure 5. Type I sums of squares in an ANOVA of the sources of variation explaining observed $\Delta T\left({ }^{\circ} \mathrm{C}\right)$, where $\Delta T=T_{c}-T_{\text {air }}$, expressed as a percentage of the total sums of squares for (a) the FACE-Maricopa and (b) China Wheat experiments. Sources of variation were controlled for in the following order for FACE-Maricopa: $\mathrm{VPD}_{\mathrm{Tmax}}$, $\mathrm{ET}_{\mathrm{o}}$, daily cumulative solar radiation, windspeed, year, $\mathrm{CO}_{2}$ (year), nitrogen 
(year) and water (year); and for China Wheat: $\mathrm{VPD}_{\mathrm{Tmax}}, \mathrm{ET}_{\mathrm{o}}$, daily cumulative solar radiation, windspeed, site, year (site) and water (site x year), as indicated from bottom to top in both panels.

From the analyses of variance for FACE-Maricopa, $\Delta T$ simulations from all crop models explained a significant portion of variation in observed $\Delta T$, but this portion ranged from $5 \%$ to $35 \%$ (Fig. 6a). The reference EMP model (HU) explained 50\%, while the e.median explained $45 \%$. Of the three $T_{\mathrm{c}}$ model approaches, simulations of $\Delta T$ by the EBSC models explained $34 \%$ of the variation in observed $\Delta T$, more than either of EBN (19\%) or EMP (20\%) types. The models differed in how much variation remained across years and the various treatment factors. For $\mathrm{CO}_{2}$ treatment effects, in the EBSC models, only $1 \%$ variation remained unexplained by L5 whereas $5 \%$ remained unexplained by SP. The within group differences were less pronounced for the other two modelling approaches. The three modelling approaches were similar with regards to explaining variation due to nitrogen with the EMP models explaining the greatest variation. Wider variation within modelling approaches was observed for the amount of unexplained variation related to water supply level. For the China Wheat experiment, all models except SQ explained a significant portion of variation in observed $\Delta T$, though the amount of variation explained was generally lower than the variation explained in the FACE-Maricopa experiment (Fig. 6b). On average the EMP (excluding HU), EBN and EBSC models explained 24, 7 and $40 \%$ of variation in observed $\Delta T$, respectively while the reference model $\mathrm{HU}$ explained $51 \%$ of variation. All models left a large amount of variation due to site unexplained, at 17, 28 and 17\% for the EMP, EBN and EBSC model averages, respectively. There was no strong pattern within modelling approach as to how much variation remained after controlling for year. On average, EBSC models had only 5\% variation due to water treatment remaining, whereas EMP and EBN models had $16 \%$ and $20 \%$ unexplained variation due to water treatment respectively, and the reference HU $8 \%$ remaining. 
(a)

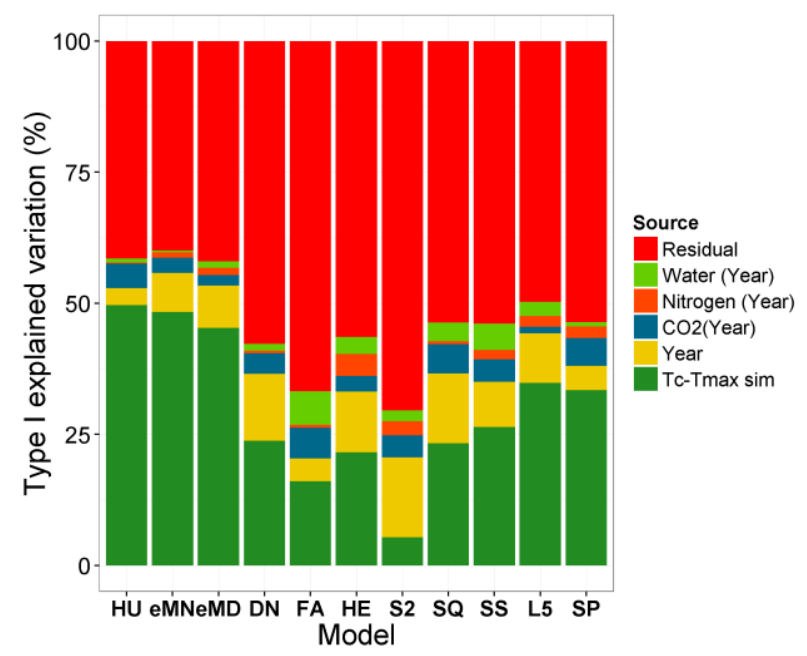

(b)

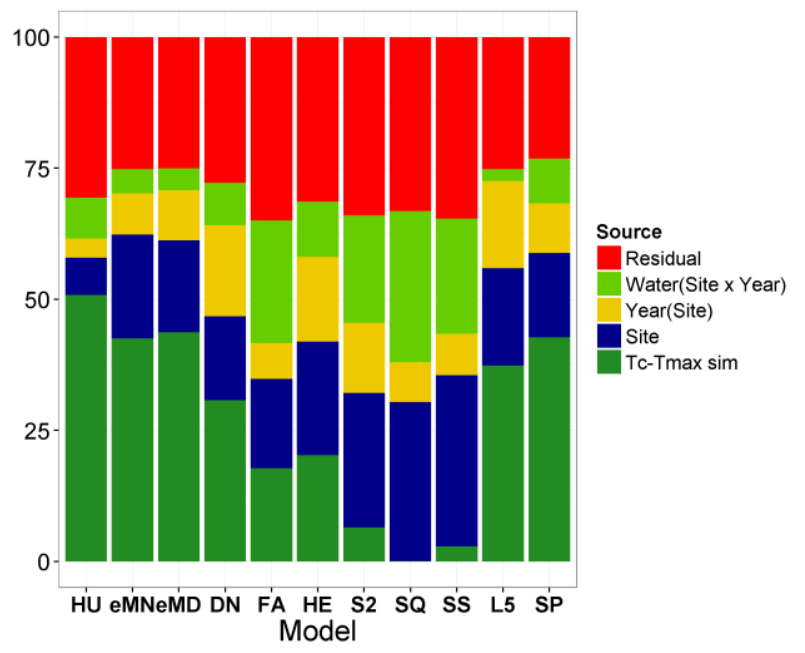

Figure 6. Type I sums of squares in an ANOVA of the sources of variation explaining observed $\Delta T\left({ }^{\circ} \mathrm{C}\right)$, where $\Delta T=T_{c}-T_{\text {air }}$, expressed as a percentage of the total sums of squares for (a) the FACE-Maricopa and (b) the China Wheat experiments. Sources of variation for FACE-Maricopa (a) were controlled for in the following order: simulated $\Delta T$ (green), year (yellow), $\mathrm{CO}_{2}$ (year) (blue), nitrogen (year) (orange) and water (year) (light green), with the residual error in red, as indicated from bottom to top. Sources of variation for China Wheat (b) were controlled for in the following order: simulated $\Delta T$ (green), site (dark blue), year (site) (yellow), water (site $\times$ year) (light green), with the residual error in red, as indicated from bottom to top in the figure. In both panels, the percentage sums of square terms are shown from left for the reference EMP model HU, the mean across models (e.MN), the model median (e.MD), the two EMP models (DN and FA), four EBN models (HE, S2, SQ and SS) and two ENSC models (L5 and SP).

Considering the drivers of variability in observed $\Delta T$ as well as the remaining residuals, we explored what variability the simulated $\Delta T$ accounted for and what remained unexplained. As the analyses used Type I Sums of Squares, caution is needed in directly comparing the terms between the ANOVAs with and without the simulations. As a first step, we noted that the simulations explained at most 50\% (HU reference) and 34\% (EBSC approach) of the variation in observed $\Delta T$ in the FACE-Maricopa experiment. Likewise, $\mathrm{VPD}_{\mathrm{Tmax}}$ explained $38 \%$ of the variation in the observations when considering only 
environmental or treatment factors. Therefore, we endeavored to test the hypothesis that the models explained more variation than the $\mathrm{VPD}_{\mathrm{Tmax}}$ did by performing an ANOVA in which $\mathrm{VPD}_{\mathrm{Tmax}}$ was controlled for first, followed by simulated $\Delta T$. For the FACE experiment, all models explained more variation than $\mathrm{VPD}_{\mathrm{Tmax}}$, whereas in the China Wheat experiment two of the EBN models were unable to explain more variation in observations after $\mathrm{VPD}_{\mathrm{Tmax}}$ was controlled for (Table 4). In both experiments, the HU reference explained the highest level of variation followed by the EBSC, EMP and EBN models.

Variation between observed and simulated $\Delta T$ also might result from differences in how well the models simulated crop growth, including effects of nitrogen or water regimes. For example, if a given model simulated values of LAI that were unrealistically low, this might lead to underestimation of transpiration. We tested for an effect of simulated LAI on the residual of observed vs. simulated $\Delta T$ (SI Fig. S3). Allowing for a site effect, LAI and its interaction with site explained from $2.6 \%$ to $12.6 \%$ of the variation $(P<0.01$, data not shown), suggesting that skill in simulating crop growth also contributed a relatively small proportion of the error in simulating $\Delta T$.

Table 4. Type I sums of squares variation (\%) explained by simulated values of $\Delta T$ after variation due to $\mathrm{VPD}_{\text {Tmax }}$ was controlled for expressed as a percentage of total variation across years, production conditions and $\mathrm{CO}_{2}$ factors in the FACE-Maricopa experiment and across years, locations and water supply treatment in the China Wheat experiment. Only values that were statistically significant at $P=$ 0.05 are reported. e.mean and e.median are the mean and median across models, respectively.

\begin{tabular}{llcc}
\hline $\boldsymbol{T}_{\mathbf{c}}$ model type & Model & FACE & China Wheat \\
\hline REF & e.mean & 15.9 & 42.9 \\
REF & e.median & 13.0 & 42.9 \\
REF-EMP & HU & 17.0 & 51.0
\end{tabular}




\begin{tabular}{lllc} 
EMP & DN & 5.7 & 36.0 \\
EMP & FA & 2.7 & 17.7 \\
EBN & HE & 1.5 & 19.3 \\
EBN & SQ & 5.5 & - \\
EBN & SS & 5.9 & - \\
EBN & S2 & 3.2 & 5.6 \\
EBSC & L5 & 7.3 & 36.4 \\
EBSC & SP & 8.3 & 42.2 \\
\hline
\end{tabular}

\section{Response to $\mathrm{CO}_{2}$}

Modeled response of $T_{c}$ to $\mathrm{CO}_{2}$ was assessed for all observational pairs of the difference in $T_{c}$ at elevated and ambient $\mathrm{CO}_{2}$ for each water supply and nitrogen fertilizer treatments (Fig. 7). The observed $\mathrm{CO}_{2}$ response exhibited variation that the models would not necessarily be expected to reproduce. Two of the models, the EBN model HE and the EBSC model L5, reproduced the median response in the observations, while the EMP model DN captures some response in the water supply treatments, though not in the nitrogen supply treatments. The ability of the various models to capture the response of $T_{c}$ to water and nitrogen treatments is presented in the SI (Fig. S5), though the variation is high due to the variation in water and nitrogen stress levels over the course of the season. 

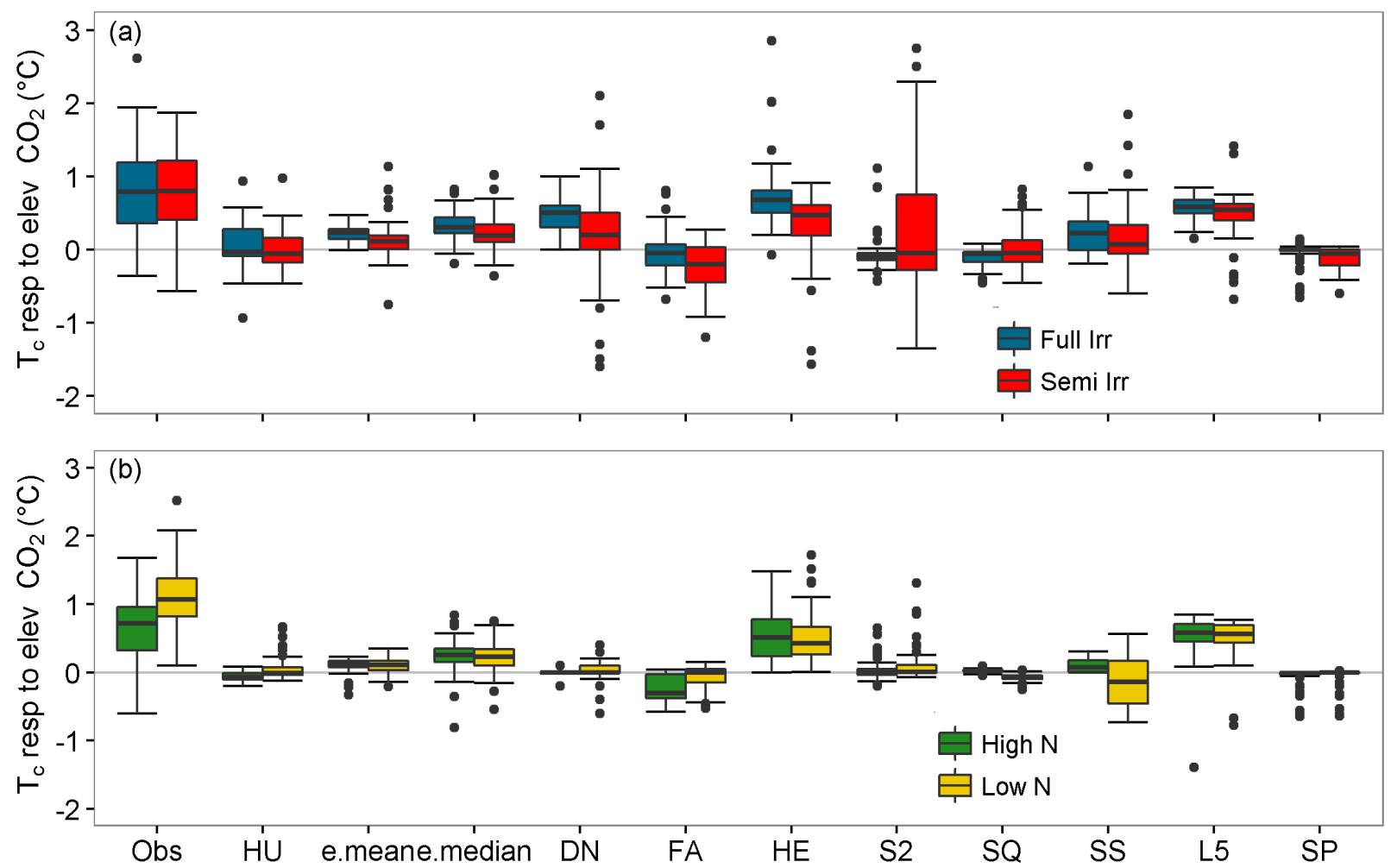

Figure 7. Absolute $T_{c}$ response $\left({ }^{\circ} \mathrm{C}\right)$ to elevated atmospheric $\mathrm{CO}_{2}$ concentration relative to ambient $\mathrm{CO}_{2}$ in the FACE-Maricopa experiment in (a) 1993 and 1994 for across water supply treatment levels and (b) 1996 and 1997 across nitrogen fertilizer treatment levels. The boxes show the $25^{\text {th }}$ and $75^{\text {th }}$ percentile of the paired data points, the top whisker indicates either the maximum value or the $75^{\text {th }}$ percentile value plus 1.5 times the difference between the $75^{\text {th }}$ and $25^{\text {th }}$ percentile, the circles above the top whisker indicate any values larger than the value of the top whisker, the bottom whisker indicates either the minimum value or the $25^{\text {th }}$ percentile value minus 1.5 times the difference between the $75^{\text {th }}$ and $25^{\text {th }}$ percentile and the circles beneath the bottom whisker indicate any values smaller than the bottom whisker. In both panels, the response is presented from left for the reference EMP model HU, the mean (e.mean) and the median (e.median) across models, the two EMP models (DN, FA), four EBN models (HE, S2, SQ, SS) and two ENSC models (L5, SP).

\section{Discussion}




\section{Extension of and limitations of the study}

To our knowledge, this is the first study to compare approaches for simulation of $T_{c}$ over a wide range of locations and management conditions, extending previous $T_{c}$ and $r_{\mathrm{a}}$ model comparisons by Webber et al. (2017) and Liu et al. (2007), respectively. Despite the wide range of production conditions and latitudes considered, all study locations were continental, and a high humidity site with low VPD was not included. Many tropical African, Asian and South American regions fall into the latter category, and $T_{c}$ may be expected to rise above $T_{a i r}$ in periods of soil water stress. Given that daily maximum temperatures are already close to high temperature thresholds in these regions (Schlenker and Lobell, 2010; Lobell et al., 2011) and is expected to increase with climate change, further study is warranted. Further, the EMP $T_{c}$ models evaluated in this study were originally developed using data from Maricopa either directly in this study or based on relationships reported by Pinter, Zipoli et al (1990). It should be noted that the HU model was originally developed from two sites in Germany, but before parameterization with the FACEMaricopa data, it had performance similar to the other EMP models (Table S3).

Our study also did not consider genotypic variability in the degree of canopy cooling, although stomatal conductance and the degree of canopy temperature depression typically varies among genotypes under heat (Amani et al., 1996) and also varies between spikes and leaves, with the reproductive spike being warmer than leaves at least partially due to lower stomatal density (Pinter et al., 1990; Ayeneh et al., 2002). However, there is also evidence that floral structures may show differential ability to cool at key reproductive stages (Steinmeyer et al., 2013). We know of no studies evaluating models for their ability to distinguish canopy temperature depression across varieties. This is an obvious next step for crop models to aid in investigating genotype by environment by management $(\mathrm{G} \times \mathrm{E} \times \mathrm{M})$ interactions for heat stress risk assessments. The fact that aerial instrument platforms can now assess $T_{c}$ at high throughput -and with greater precision than using ground based approaches- (Tattaris et al., 2016) provides an opportunity to calibrate and validate models for this trait on a large scale. 
Related to assisting $(\mathrm{G} \times \mathrm{E} \times \mathrm{M})$, the current study did not evaluate whether consideration of simulated $T_{c}$ can improve heat stress simulations of production, as the focus was on the skill of $T_{c}$ routines across production conditions and locations. Some authors (Hatfield et al., 1984) have argued that canopy temperature in cereal crops is a poor indicator of heat stress, as the spikes will generally be at the same temperature as the air rather than that of the bulk canopy. In fact, a canopy temperature gradient within the crop, varying between canopy and spike in wheat (Amani et al., 1996; Ayeneh et al., 2002), or the ear in maize (Edreira and Otegui, 2012), has been reported. In the case of wheat, although the spike was 0.5 to $1^{\circ} \mathrm{C}$ warmer than the canopy in Obregon, Mexico, under irrigated conditions, it still obtained a temperature depression relative to $T_{\text {air }}$ of 3 to $4.3^{\circ} \mathrm{C}$ (Ayeneh et al., 2002). That the spike temperature will differ from $T_{a i r}$ and be close to $T_{c}$ is also supported by Amani et al. (1996). In any case, if $T_{c}$ is to replace $T_{a i r}$ in simulation of heat stress effects, models will need re-calibration or parameterization.

A further issue is that our analysis of the drivers of observed $\Delta T$ were limited in that we used mainly the summary weather data as used by the crop models as input (i.e., daily radiation sum, average wind speed, daily maximum temperature and corresponding VPD) whereas actual $\Delta T$ is driven by instantaneous values of VPD, air temperature, and water stress. Further study of this issue is possible with our FACEMaricopa dataset, making use of sub-hourly data (Kimball et al., 1999). However, temperature and vapor profiles with the crop's boundary layer vary rapidly as the distance from the crop surface increases (Monteith and Unsworth, 2007), such that conducting an energy balance of a cropped surface is sensitive to where atmospheric conditions are measured (Jarvis and McNaughton, 1986). As the objective of this study was to investigate $T_{c}$ in the context of simple approaches to model heat stress, we believe a daily analysis, considering daily $T_{\max }$ and $V P D_{\text {Tmax }}$ was appropriate. A future challenge will be to extend the use of $T_{c}$ to growth and development processes that respond to temperatures other than $T_{\max }$.

\section{Potential for model improvement}


In our current study, many of the comparisons were based on comparing individual model performance against the observations and testing model performance for simulating crop response to nitrogen stress, water deficits or atmospheric $\mathrm{CO}_{2}$ concentration. This contrasts with our previous model intercomparison (Webber et al., 2017), which placed more emphasis on the approach to simulating $T_{c}$ (i.e., EMP, EBN, ENSC). There was sometimes considerable variation within a modelling approach that may be related to how sensitive the crop models were to nitrogen or water availability, which will affect stomatal conductance and LAI, both of which feedback to $T_{c}$ simulations as discussed further below. Nevertheless, comparing across the $R^{2}$ (Table 2 and S1), RMSE (Tables 3 and S2) and level of variation explained (Fig. 6), as a group, the EBSC models performed better than the EMP or EBN models, as in Webber et al. (2017). This is particularly evident when the performance of the models for the China Wheat experiment where the EBSC models could explain 30 to $40 \%$ of the variability in the observed $\Delta T$ and had $R^{2}$ values of $0.27-0.30$ for the rainfed treatments across sites, whereas three of the four EBN models had no significant correlations, and the EMP models had an average $R^{2}$ value of 0.13 . However, in the FACE water stress treatments as well as the high $\mathrm{N}$ and all $\mathrm{CO}_{2}$ treatments, the empirical $\mathrm{HU}$ model performed markedly better than even the EBCS models, though the difference was reduced or reversed in the irrigated and nitrogen limited treatments. Collectively, this suggests the hypothesis that simulation of $T_{\mathrm{c}}$ across diverse environments and conditions is improved with stability correction to account for the differences in $r_{a}$ or that empirical models must be fit on sufficient data for a particular environment. Our study does not allow us to definitely conclude whether the superior performance of the EBSC models compared to other models in the ensemble is due to stability correction or rather due to other factors (e.g. improved simulation of evapotranspiration), as discussed in more detail below. However, there was a clear relationship between how much variation in observed $\Delta T$ could be explained by simulated $\Delta T$, and the remaining variation variability explained by stability conditions, as indicated by the bulk Richardson number (Ri; Fig 8). This indicates that the reference empirical model HU and the EBSC models were able to capture more variability associated with boundary layer stability conditions than the other models. To more directly test this, it would be better to compare our modelled estimates of $r_{a}$ to measurements of 
turbulence obtained using a 3D sonic anemometer, but such measurements were not made in the FACE experiment. Despite the smaller total error for the EBSC models, in some cases the error, $T_{c, o b s}-T_{c, s i m}$, was still correlated with $\mathrm{Ri}$ and exhibited a positive slope demonstrating that the stability conditions were not completely corrected for, although the Ri relation with error for EBSC models was generally less than that for the EBN or EMP models (Figs S6 and S7, Tables S3 and S4). Surprisingly, the error associated with one of the EBN models (HE) generally exhibited less correlation (and lower slope) with Ri, though the simulations explained less variation in observed $\Delta \mathrm{T}$ than did the EBSC models. The question of whether stability correction or an empirical approach is needed may simply depend on the application, the extent of the study and the data available to construct or calibrate an empirical model.

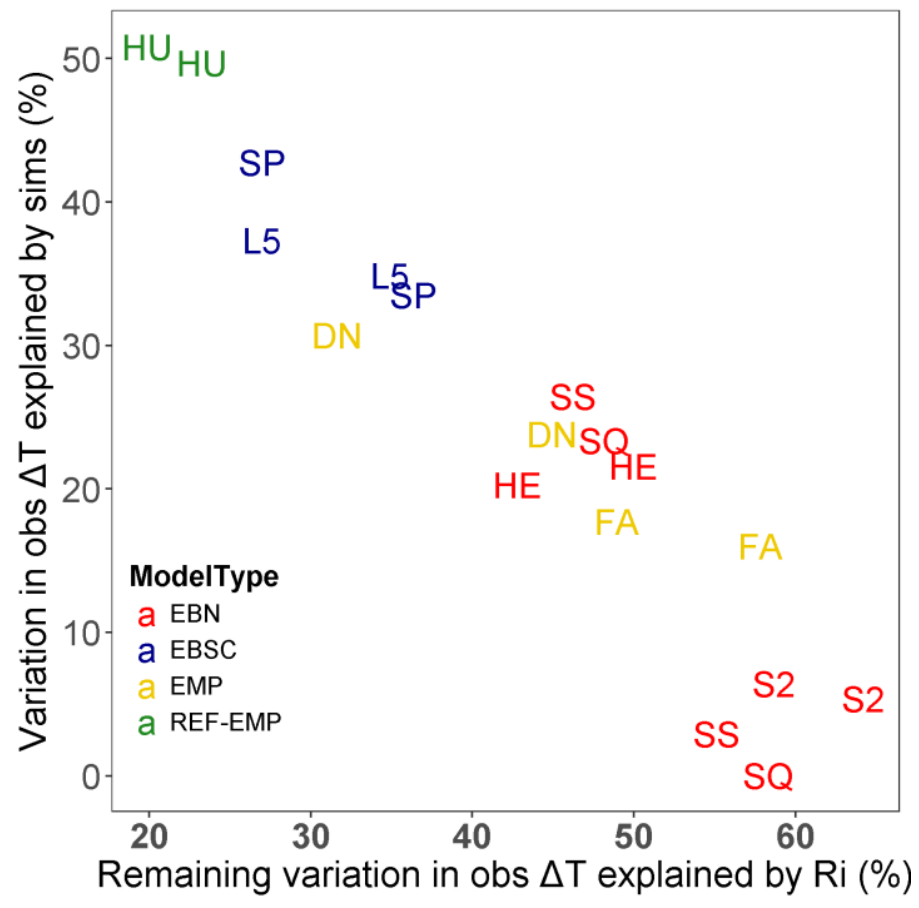

Figure 8. Type I sums of squares in an ANOVA of variation in observed $\Delta T=T_{c}-T_{\text {air }}\left({ }^{\circ} \mathrm{C}\right)$ explained by simulations of $\Delta T$, expressed as a percentage of the total sums of squares, for each of the FACE-Maricopa and the China Wheat experiments plotted against the remaining Type I sums of squares variation explained by the Richardson number (Ri). Different colors indicate the model approach to simulate Tc, with EBN models in red, EBSC models in green and EMP models in blue. The letter indicates the model 
name and the two occurrences of each model are to indicate the values for each of the FACE-Maricopa and China Wheat experiments which are not distinguished in this figure.

Beyond corrections for stability, ability to correctly simulate $T_{c}$ depended on the respective models' response to water, nitrogen and $\mathrm{CO}_{2}$ levels. This presumably explains why unlike Webber et al. (2017), this study did not reveal as decisively that the EBN models were consistently worse than EMP models at the Maricopa site. It was surprising to us that the EMP models performed better for the China Wheat dataset than the EBN models, as they were developed based on relationships derived in Maricopa. This is particularly the case for the HU model, which although treated as a reference model for FACE-Maricopa, was not trained on the data for the China Wheat experiment. However, as already discussed all study locations were continental and do not include high humidity conditions. Interestingly, no models were able to perform well under the semi-irrigated conditions in the FACE Maricopa experiment, including $\mathrm{HU}$, and further study is needed to understand the drivers of variation in these observations. It should be noted that in the first step of this study in which limited $T_{c}$ observations were available for calibration, the HU model performed similar to the other EMP models (SI material, Table S3). However, we place limited emphasis on the first set of simulations as some models had prior access to the observations and other than $\mathrm{HU}$, there was limited ability to calibrate the $T_{c}$ simulations to observations.

After $\mathrm{VPD}_{\text {Tmax }}$ was accounted for, the simulations were able to explain 4.2, 4.0 and $7.8 \%$ of the variation for the EMP, EBN and EBSC approaches for FACE-Maricopa, respectively. The agreement among these values contrasted with the wide variation in skill in capturing the variation in observed $\Delta T$ across modelling approaches suggests that the difference among the simulation approaches relates to how well models capture the effects of VPD driving transpirational cooling or lack thereof. In general, the EBSC models also explained the greatest amount of variation across the well-watered treatments for both FACE and China Wheat experiments, in which cooling is largely driven by $\operatorname{VPD}_{\mathrm{Tmax}}$ and air is typically stable (SI Material, Tables S2 and S3). The superior performance of the EBSC models compared to other 
models in the ensemble was less pronounced when observations over all water stressed treatments from both experiments were combined. Furthermore, within the EBN approaches, there was wide variation in terms of the variation explained across water stress treatments. Correct simulation of the response of $T_{c}$ to water stress requires that a model must correctly simulate root depth, soil water dynamics, water demand and uptake as well as the crop response to water stress. Therefore, poor performance of a $T_{c}$ approach here may reflect either the ability of a given crop model to correctly simulate water use and water stress or the $T_{c}$ model's sensitivity to water stress. A further caveat to the interpretation of the results under waterlimited conditions is that the HU reference model trained on the FACE-Maricopa data could only explain $22 \%$ of variation in the water stressed observations from that experiment, but when observations were pooled with the China Wheat experiment, its correlation with observed $\Delta T$ increased to $43 \%$. More work is needed to understand the source of variation in this treatment.

Regarding the effect of different simulations of evaporative demand and water use on simulated $T_{\mathrm{c}}$, consider the two EBSC models, L5 and SP, which share the same $T_{\mathrm{c}}$ model, but differ in other respects. Considering the FACE irrigated treatments, where soil water deficit would have been minimal, the differences between their simulations are probably related to the degree of evaporative cooling and resulting stability conditions, as L5, with higher correlation for these treatments, generally simulates higher $\mathrm{ET}_{\mathrm{o}}$ (Webber et al., 2016a) with the FAO-56 methodology (Allen et al., 1998) than SP with a Penman based approach (Penman, 1948). However, the SP model had better performance considering the water limited conditions and the China Wheat experiment, in which correct simulation of the water balance and various feedbacks on LAI would have been more important, as both feedback onto $r_{\mathrm{a}}$ and $T_{c}$. Clearly a prerequisite of improving $\mathrm{T}_{\mathrm{c}}$ simulations is to have good estimates of $\mathrm{ET}_{0}$ and simulation of soil water dynamics. For the nitrogen treatments, there was no large pattern across model groups, although the EMP models were able to explain more variation than the other types (data not shown). Likewise, there was little differentiation between the model groups with respect to explaining variation due to $\mathrm{CO}_{2}$ levels with one model in each of the EBN and EBSC capturing the median response (Fig. 7). This suggests that 
regardless of the approach, it should be possible to include this response in $T_{c}$ models and this study identified this as a relatively straightforward model improvement. As previously stated, while the two EBSC models used the same $T_{c}$ model, L5 accounted for $\mathrm{CO}_{2}$ effects on canopy resistance $\left(r_{\mathrm{c}}\right)$ term, such that canopy resistance increased by $20 \%$ as atmospheric $\mathrm{CO}_{2}$ increased from 370 to $550 \mathrm{ppm}$. The $T_{c}$ model of L5 did not feedback onto the calculation of transpiration. Instead, it used the crop coefficient and $\mathrm{ET}_{\mathrm{o}}$ concept (Allen et al., 1998), so its daily potential transpiration rate was adjusted to limit water use under elevated $\mathrm{CO}_{2}$ (Zhao et al., 2015). However, this strategy was insufficient to describe the reduced stomatal conductance on an hourly basis to determine $T_{c}$ in our previous study (Webber et al., 2016b), suggesting that further model development is needed. Collectively, beyond accounting for stability conditions or having a strong empirical model built on adequate data, correct simulation of $T_{c}$ across a range of conditions also requires that crop models account for water demand, soil water dynamics and response to $\mathrm{CO}_{2}$.

\section{Use of $T_{c}$ in climate change impact assessments}

As the frequency of crop heat stress increases with climate change (Field, 2012), it will become increasingly important for crop models to improve their consideration of the impacts of heat stress damage on crop yields (White et al., 2011). Observational evidence demonstrates that transpirational cooling in irrigated systems (Lobell et al., 2008; Puma and Cook, 2010) has mitigated damages during periods of high temperatures in past episodes of high temperature in maize production in the US (Carter et al., 2016). Likewise, Lobell et al (2011) detected more severe yield losses due to the number of hot days in drought as compared to well-watered conditions. Despite this widely documented and physically well understood phenomenon, few crop models consider the interaction of high temperature and water availability, suggesting heat stress assessments will likely overestimate damages under irrigated conditions, and this bias will increase as climates become warmer (Siebert et al., 2017). Consideration of $T_{\mathrm{c}}$ explicitly accounts for this interaction and should improve the accuracy of climate change impact assessments, particularly for irrigated systems (Rezaei et al., 2015). However, consideration of heat and 
drought stress is also expected to be important for tropical regions where daily maximum temperatures are already close to limits for crop heat stress and short episodes of high temperature and drought are likely to coincide. Correct simulation of this will depend on a good approach to simulating $T_{c}$ as well as adequate depiction of crop water demand and use dynamics and possible interactions with $\mathrm{CO}_{2}$ concentrations.

\section{Acknowledgments}

We thank AgMIP for support. HW and FE contributions were funded by the Federal Ministry of Education and Research (BMBF) through WASCAL (West African Science Service Center on Climate Change and Adapted Land Use). Additionally, FE was supported from the German Science Foundation (project EW 119/5-1). FE also acknowledges support from the FACCE JPI MACSUR project (2812ERA115) through the German Federal Ministry of Education and Research. S.A. and B.T.K received support from the International Food Policy Research Institute (IFPRI) through the Global Futures and Strategic Foresight project, the CGIAR Research Program on Climate Change, Agriculture and Food Security (CCAFS) and the CGIAR Research Program on Wheat. EER was funded through the German Federal Ministry of Economic Cooperation and Development (Project: PARI). PM and AB acknowledge support from the FACCE JPI MACSUR project (031A103B) through the metaprogram Adaptation of Agriculture and Forests to Climate Change (AAFCC) of the French National Institute for Agricultural Research (INRA). Rothamsted Research receives support from the Biotechnological and Biological Sciences Research Council of the UK. JEO was funded from the FACCE MACSUR project by Innovation Fund Denmark. KCK acknowledge the support from JPI FACCE MACSUR2 through the German Ministry of Education and Research (031B0039C). MB and RF were funded from JPI FACCE MACSUR2 through the Italian Ministry for Agricultural, Food and Forestry Policies. HK, AMR and AL were supported from the German Science Foundation (project KA 3046/8-1). USDA is an equal opportunity provider and employer. 


\section{References}

Allen, R.G., Pereira, L.S., Raes, D., Smith, M., 1998. Crop evapotranspiration-Guidelines for computing crop water requirements-FAO Irrigation and drainage paper 56. FAO, Rome 300, 6541.

Amani, I., Fischer, R., Reynolds, M., 1996. Canopy temperature depression association with yield of irrigated spring wheat cultivars in a hot climate. Journal of Agronomy and Crop Science 176, 119-129.

Anderson, C.J., Babcock, B.A., Peng, Y., Gassman, P.W., Campbell, T.D., 2015. Placing bounds on extreme temperature response of maize. Environmental Research Letters 10, 124001.

Asseng, S., Foster, I., Turner, N.C., 2011. The impact of temperature variability on wheat yields. Global Change Biology 17, 997-1012.

Ayeneh, A., Van Ginkel, M., Reynolds, M., Ammar, K., 2002. Comparison of leaf, spike, peduncle and canopy temperature depression in wheat under heat stress. Field Crops Research 79, 173-184.

Blum, A., Mayer, J., Gozlan, G., 1982. Infrared thermal sensing of plant canopies as a screening technique for dehydration avoidance in wheat. Field Crops Research 5, 137-146.

Blum, A., Shpiler, L., Golan, G., Mayer, J., 1989. Yield stability and canopy temperature of wheat genotypes under drought-stress. Field Crops Research 22, 289-296.

Carter, E.K., Melkonian, J., Riha, S.J., Shaw, S.B., 2016. Separating heat stress from moisture stress: analyzing yield response to high temperature in irrigated maize. Environmental Research Letters 11, 094012.

Challinor, A., Wheeler, T., Craufurd, P., Slingo, J., 2005. Simulation of the impact of high temperature stress on annual crop yields. Agricultural and Forest Meteorology 135, 180-189.

Clawson, K., Jackson, R., Pinter, P., 1989. Evaluating plant water stress with canopy temperature differences. Agronomy Journal 81, 858-863.

Doltra, J., Lægdsmand, M., Olesen, J.E., 2014. Impacts of projected climate change on productivity and nitrogen leaching of crop rotations in arable and pig farming systems in Denmark. The Journal of Agricultural Science 152, 75-92.

Doltra, J., Olesen, J.E., Báez, D., Louro, A., Chirinda, N., 2015. Modeling nitrous oxide emissions from organic and conventional cereal-based cropping systems under different management, soil and climate factors. European Journal of Agronomy 66, 8-20.

Edreira, J.I.R., Otegui, M.E., 2012. Heat stress in temperate and tropical maize hybrids: Differences in crop growth, biomass partitioning and reserves use. Field Crops Research 130, 8798.

Ehlers, W., Hamblin, A., Tennant, D., Van der Ploeg, R., 1991. Root system parameters determining water uptake of field crops. Irrig Sci 12, 115-124.

Field, C.B., 2012. Managing the risks of extreme events and disasters to advance climate change adaptation: special report of the intergovernmental panel on climate change. Cambridge University Press.

Gabaldón-Leal, C., Webber, H., Otegui, M.E., Slafer, G.A., Ordóñez, R.A., Gaiser, T., Lorite, I.J., Ruiz-Ramos, M., Ewert, F., 2016. Modelling the impact of heat stress on maize yield formation. Field Crops Research 198, 226-237. 
Gaiser, T., Perkons, U., Küpper, P.M., Kautz, T., Uteau-Puschmann, D., Ewert, F., Enders, A., Krauss, G., 2013. Modeling biopore effects on root growth and biomass production on soils with pronounced sub-soil clay accumulation. Ecological Modelling 256, 6-15.

Gourdji, S.M., Mathews, K.L., Reynolds, M., Crossa, J., Lobell, D.B., 2013. An assessment of wheat yield sensitivity and breeding gains in hot environments. Proceedings of the Royal Society of London B: Biological Sciences 280, 20122190.

Gray, S.B., Dermody, O., Klein, S.P., Locke, A.M., McGrath, J.M., Paul, R.E., Rosenthal, D.M., Ruiz-Vera, U.M., Siebers, M.H., Strellner, R., 2016. Intensifying drought eliminates the expected benefits of elevated carbon dioxide for soybean. Nature Plants 2, 16132.

Hatfield, J., Pinter, P., Chasseray, E., Ezra, C., Reginato, R., Idso, S., Jackson, R., 1984. Effects of panicles on infrared thermometer measurements of canopy temperature in wheat. Agricultural and Forest Meteorology 32, 97-105.

Hatfield, J., Quisenberry, J., Dilbeck, R., 1987. Use of canopy temperatures of identify water conservation in cotton germplasm. Crop science 27, 269-273.

Hatfield, J.L., 2016. Increased Temperatures Have Dramatic Effects on Growth and Grain Yield of Three Maize Hybrids. Agricultural \& Environmental Letters 1.

Haun, J., 1973. Visual quantification of wheat development. Agronomy Journal 65, 116-119.

Hawkins, E., Fricker, T.E., Challinor, A.J., Ferro, C.A., Ho, C.K., Osborne, T.M., 2013. Increasing influence of heat stress on French maize yields from the 1960s to the 2030s. Global Change Biology 19, 937-947.

Hendrey, G.R., 1993. FACE: Free-air CO2 enrichment for plant research in the field. CK Smoley.

Hoogenboom, G., Huck, M.G., 1986. Rootsimu v4. 0: a dynamic simulation of root growth, water uptake, and biomass partitioning in a soil-plant-atmosphere continuum: update and documentation. Agronomy and soils departmental series-Auburn University, Alabama Agricultural Experiment Station (USA).

Hunsaker, D., Kimball, B., Pinter Jr, P., LaMorte, R., Wall, G., 1996. Carbon dioxide enrichment and irrigation effects on wheat evapotranspiration and water use efficiency. Transactions of the ASAE 39, 1345-1355.

Hunsaker, D., Kimball, B., Pinter, P., Wall, G., LaMorte, R., Adamsen, F., Leavitt, S., Thompson, T., Matthias, A., Brooks, T., 2000. CO 2 enrichment and soil nitrogen effects on wheat evapotranspiration and water use efficiency. Agricultural and Forest Meteorology 104, 85105.

Idso, S., Reginato, R., Reicosky, D., Hatfield, J., 1981. Determining soil-induced plant water potential depressions in alfalfa by means of infrared thermometry. Agronomy Journal 73, 826830.

Jackson, R., Reginato, R., Idso, S., 1977. Wheat canopy temperature: a practical tool for evaluating water requirements. Water Resources Research 13, 651-656.

Jackson, R.D., Idso, S., Reginato, R., Pinter, P., 1981. Canopy temperature as a crop water stress indicator. Water Resources Research 17, 1133-1138.

Jamieson, P., Brooking, I., Porter, J., Wilson, D., 1995. Prediction of leaf appearance in wheat: a question of temperature. Field Crops Research 41, 35-44.

Jamieson, P., Semenov, M., 2000. Modelling nitrogen uptake and redistribution in wheat. Field Crops Research 68, 21-29. 
Jamieson, P.D., Porter, J.R., Goudriaan, J., Ritchie, J.T., van Keulen, H., Stol, W., 1998. A comparison of the models AFRCWHEAT2, CERES-wheat, Sirius, SUCROS2 and SWHEAT with measurements from wheat grown under drought. Field Crops Research 55, 23-44.

Jarvis, P.G., McNaughton, K., 1986. Stomatal control of transpiration: scaling up from leaf to region. Advances in ecological research 15, 1-49.

Johnen, T., Boettcher, U., Kage, H., 2012. A variable thermal time of the double ridge to flag leaf emergence phase improves the predictive quality of a CERES-Wheat type phenology model. Computers and Electronics in Agriculture 89, 62-69.

Kersebaum, K., 2011. Special features of the HERMES model and additional procedures for parameterization, calibration, validation, and applications. Methods of Introducing System Models into Agricultural Research, 65-94.

Kersebaum, K., Nendel, C., 2014. Site-specific impacts of climate change on wheat production across regions of Germany using different CO 2 response functions. European Journal of Agronomy 52, 22-32.

Kimball, B., LaMorte, R., Pinter, P., Wall, G., Hunsaker, D., Adamsen, F., Leavitt, S., Thompson, T., Matthias, A., Brooks, T., 1999. Free-air CO2 enrichment and soil nitrogen effects on energy balance and evapotranspiration of wheat. Water Resources Research 35, 1179-1190.

Kimball, B.A., Pinter Jr, P.J., LaMorte, R.L., Leavitt, S.W., Hunsaker, D.J., Wall, G.W., Wechsung, F., Wechsung, G., Bloom, A.J., White, J.W., 2017. Data from the Arizona FACE (Free-Air CO2 Enrichment) Experiments on Wheat at Ample and Limiting Levels of Water and Nitrogen. Open Data Journal for Agricultural Research 3.

Kimball, B.A., Pinter, P., Garcia, R.L., LaMorte, R., Wall, G.W., Hunsaker, D.J., Wechsung, G., Wechsung, F., 1995. Productivity and water use of wheat under free-air CO2 enrichment. Global Change Biology 1, 429-442.

Lawless, C., Semenov, M., Jamieson, P., 2005. A wheat canopy model linking leaf area and phenology. European Journal of Agronomy 22, 19-32.

Leakey, A.D., Bernacchi, C.J., Ort, D.R., Long, S.P., 2006. Long-term growth of soybean at elevated [CO2] does not cause acclimation of stomatal conductance under fully open-air conditions. Plant, cell \& environment 29, 1794-1800.

Liu, S., Lu, L., Mao, D., Jia, L., 2007. Evaluating parameterizations of aerodynamic resistance to heat transfer using field measurements. Hydrology and earth system sciences 11, 769-783.

Lobell, D.B., Asseng, S., 2017. Comparing estimates of climate change impacts from processbased and statistical crop models. Environmental Research Letters 12, 015001.

Lobell, D.B., Bänziger, M., Magorokosho, C., Vivek, B., 2011. Nonlinear heat effects on African maize as evidenced by historical yield trials. Nature Climate Change 1, 42-45.

Lobell, D.B., Bonfils, C.J., Kueppers, L.M., Snyder, M.A., 2008. Irrigation cooling effect on temperature and heat index extremes. Geophysical Research Letters 35.

Lobell, D.B., Hammer, G.L., McLean, G., Messina, C., Roberts, M.J., Schlenker, W., 2013. The critical role of extreme heat for maize production in the United States. Nature Climate Change 3, 497-501.

Lopes, M.S., Reynolds, M.P., 2010. Partitioning of assimilates to deeper roots is associated with cooler canopies and increased yield under drought in wheat. Functional Plant Biology 37, 147156.

Mahrt, L., Ek, M., 1983. The influence of atmospheric stability on potential evaporation. Journal of Climate and Applied Meteorology 23, 222-234. 
Maiorano, A., Martre, P., Asseng, S., Ewert, F., Müller, C., Rötter, R.P., Ruane, A.C., Semenov, M.A., Wallach, D., Wang, E., 2017. Crop model improvement reduces the uncertainty of the response to temperature of multi-model ensembles. Field Crops Research 202, 5-20.

Martre, P., Jamieson, P.D., Semenov, M.A., Zyskowski, R.F., Porter, J.R., Triboi, E., 2006. Modelling protein content and composition in relation to crop nitrogen dynamics for wheat. European Journal of Agronomy 25, 138-154.

Martre, P., Wallach, D., Asseng, S., Ewert, F., Jones, J.W., Rötter, R.P., Boote, K.J., Ruane, A.C., Thorburn, P.J., Cammarano, D., 2015. Multimodel ensembles of wheat growth: many models are better than one. Global Change Biology 21, 911-925.

Monin, A., Obukhov, A., 1954. Basic laws of turbulent mixing in the surface layer of the atmosphere. Contrib. Geophys. Inst. Acad. Sci. USSR 151, e187.

Monteith, J., Unsworth, M., 2007. Principles of environmental physics. Academic Press, Burlington, USA.

Moriondo, M., Giannakopoulos, C., Bindi, M., 2011. Climate change impact assessment: the role of climate extremes in crop yield simulation. Climatic Change 104, 679-701.

Neukam, D., Ahrends, H., Luig, A., Manderscheid, R., Kage, H., 2016. Integrating wheat canopy temperatures in crop system models. Agronomy 6, 7.

Olesen, J.E., Petersen, B.M., Berntsen, J., Hansen, S., Jamieson, P., Thomsen, A., 2002. Comparison of methods for simulating effects of nitrogen on green area index and dry matter growth in winter wheat. Field Crops Research 74, 131-149.

Olivares-Villegas, J.J., Reynolds, M.P., McDonald, G.K., 2007. Drought-adaptive attributes in the Seri/Babax hexaploid wheat population. Functional Plant Biology 34, 189-203.

Penman, H.L., 1948. Natural evaporation from open water, bare soil and grass. Proceedings of the Royal Society of London. Series A. Mathematical and Physical Sciences 193, 120-145.

Pinter, P., Kimball, B., Wall, G., LaMorte, R., Hunsaker, D., Adamsen, F., Frumau, K., Vugts, H., Hendrey, G., Lewin, K., 2000. Free-air CO 2 enrichment (FACE): blower effects on wheat canopy microclimate and plant development. Agricultural and Forest Meteorology 103, 319-333. Pinter, P., Zipoli, G., Reginato, R., Jackson, R., Idso, S., Hohman, J., 1990. Canopy temperature as an indicator of differential water use and yield performance among wheat cultivars. Agricultural Water Management 18, 35-48.

Pinto, R.S., Reynolds, M.P., 2015. Common genetic basis for canopy temperature depression under heat and drought stress associated with optimized root distribution in bread wheat. Theoretical and Applied Genetics 128, 575-585.

Porter, J.R., Gawith, M., 1999. Temperatures and the growth and development of wheat: a review. European Journal of Agronomy 10, 23-36.

Porter, J.R., Xie, L., Challinor, A.J., Cochrane, K., Howden, S.M., Iqbal, M.M., Lobell, D.B., Travasso, M.I., 2014. Food security and food production systems. In: Field, C.B., Barros, V.R., Dokken, D.J., Mach, K.J., Mastrandrea, M.D., Bilir, T.E., Chatterjee, M., Ebi, K.L., Estrada, Y.O., Genova, R.C., Girma, B., Kissel, E.S., Levy, A.N., MacCracken, S., Mastrandrea, P.R., White, L.L. (Eds.), Climate Change 2014: Impacts, Adaptation, and Vulnerability. Part A: Global and Sectoral Aspects. Contribution of Working Group II to the Fifth Assessment Report of the Intergovernmental Panel of Climate Change. Cambridge University Press, Cambridge, United Kingdom and New York, NY, USA, pp. 485-533.

Prasad, P.V.V., Bheemanahalli, R., Jagadish, S.V.K., 2017. Field crops and the fear of heat stress-Opportunities, challenges and future directions. Field Crops Research 200, 114-121. 
Puma, M., Cook, B., 2010. Effects of irrigation on global climate during the 20th century. Journal of Geophysical Research: Atmospheres 115.

Ratjen, A., Kage, H., 2015. Forecasting yield via reference-and scenario calculations. Computers and Electronics in Agriculture 114, 212-220.

Ratjen, A., Kage, H., 2016. Nitrogen-limited light use efficiency in wheat crop simulators: comparing three model approaches. The Journal of Agricultural Science 154, 1090-1101.

Ratjen, A., Neukam, D., Kage, H., 2016. A Simple Drought-Sensitive Model for Leaf: Stem Partitioning of Wheat. Journal of Agronomy and Crop Science.

Reginato, R.J., Hatfield, J.L., Bauer, A., Hubbard, K.G., Blad, B.L., Verma, S.B., Kanemasu, E.T., Major, D.J., 1988. Winter wheat response to water and nitrogen in the North American Great Plains. Agricultural and Forest Meteorology 44, 105-116.

Reynolds, M., Langridge, P., 2016. Physiological breeding. Current opinion in plant biology 31, 162-171.

Rezaei, E.E., Webber, H., Gaiser, T., Naab, J., Ewert, F., 2015. Heat stress in cereals: Mechanisms and modelling. European Journal of Agronomy 64, 98-113.

Rosenzweig, C., Jones, J.W., Hatfield, J.L., Ruane, A.C., Boote, K.J., Thorburn, P., Antle, J.M., Nelson, G.C., Porter, C., Janssen, S., Asseng, S., Basso, B., Ewert, F., Wallach, D., Baigorria, G., Winter, J.M., 2013. The Agricultural Model Intercomparison and Improvement Project (AgMIP): Protocols and pilot studies. Agricultural and Forest Meteorology 170, 166-182.

Schlenker, W., Lobell, D.B., 2010. Robust negative impacts of climate change on African agriculture. Environmental Research Letters 5, 014010.

Siebert, S., Ewert, F., Rezaei, E.E., Kage, H., Graß, R., 2014. Impact of heat stress on crop yield - on the importance of considering canopy temperature. Environmental Research Letters 9, 044012.

Siebert, S., Webber, H., Zhao, G., Ewert, F., 2017. Heat stress is overestimated in climate impact studies for irrigated agriculture. Environmental Research Letters 12, 054023.

Soltani, A., Maddah, V., Sinclair, T., 2013. SSM-Wheat: a simulation model for wheat development, growth and yield. International Journal of Plant Production 7, 711-740.

Steinmeyer, F.T., Lukac, M., Reynolds, M.P., Jones, H.E., 2013. Quantifying the relationship between temperature regulation in the ear and floret development stage in wheat (Triticum aestivum L.) under heat and drought stress. Functional Plant Biology 40, 700-707.

Stratonovitch, P., Semenov, M.A., 2015. Heat tolerance around flowering in wheat identified as a key trait for increased yield potential in Europe under climate change. Journal of experimental botany, erv070.

Tattaris, M., Reynolds, M.P., Chapman, S.C., 2016. A direct comparison of remote sensing approaches for high-throughput phenotyping in plant breeding. Frontiers in Plant Science 7.

Thom, A., 1975. Momentum, mass and heat exchange of plant communities. In: Monteith, J.L. (Ed.), Vegetation and the Atmosphere. Academic Press, London, pp. 57-109.

Thom, A., Oliver, H., 1977. On Penman's equation for estimating regional evaporation. Quarterly Journal of the Royal Meteorological Society 103, 345-357.

Troy, T.J., Kipgen, C., Pal, I., 2015. The impact of climate extremes and irrigation on US crop yields. Environmental Research Letters 10, 054013.

Wall, G., Garcia, R., Kimball, B., Hunsaker, D., Pinter, P., Long, S., Osborne, C., Hendrix, D., Wechsung, F., Wechsung, G., 2006. Interactive effects of elevated carbon dioxide and drought on wheat. Agronomy Journal 98, 354-381. 
Wall, G.W., Adam, N.R., Brooks, T.J., Kimball, B.A., Pinter, P.J., LaMorte, R.L., Adamsen, F.J., Hunsaker, D.J., Wechsung, G., Wechsung, F., 2000. Acclimation response of spring wheat in a free-air $\mathrm{CO} 2$ enrichment (FACE) atmosphere with variable soil nitrogen regimes. 2. Net assimilation and stomatal conductance of leaves. Photosynthesis Research 66, 79-95.

Webb, E.K., 1970. Profile relationships: The log-linear range, and extension to strong stability. Quarterly Journal of the Royal Meteorological Society 96, 67-90.

Webber, H., Gaiser, T., Oomen, R., Teixeira, E., Zhao, G., Wallach, D., Zimmermann, A., Ewert, F., 2016a. Uncertainty in future irrigation water demand and risk of crop failure for maize in Europe. Environmental Research Letters 11, 074007.

Webber, H., Martre, P., Asseng, S., Kimball, B., White, J., Ottman, M., Wall, G.W., De Sanctis, G., Doltra, J., Grant, R., Kassie, B., Maiorano, A., Olesen, J.E., Ripoche, D., Rezaei, E.E., Semenov, M.A., Stratonovitch, P., Ewert, F., 2017. Canopy temperature for simulation of heat stress in irrigated wheat in a semi-arid environment: A multi-model comparison. Field Crops Research 202, 21-35

Webber, H.A., Ewert, F., Kimball, B., Siebert, S., White, J.W., Trawally, D., Wall, G.W., Ottman, M.J., Gaiser, T., 2016b. Simulating canopy temperature for modelling heat stress in cereals. Environmental Modelling \& Software 77, 143-155.

Wheeler, T.R., Craufurd, P.Q., Ellis, R.H., Porter, J.R., Prasad, P.V., 2000. Temperature variability and the yield of annual crops. Agriculture, Ecosystems \& Environment 82, 159-167.

White, J.W., Hoogenboom, G., Kimball, B.A., Wall, G.W., 2011. Methodologies for simulating impacts of climate change on crop production. Field Crops Research 124, 357-368.

Zadoks, J.C., Chang, T.T., Konzak, C.F., 1974. A decimal code for the growth stages of cereals. Weed research 14, 415-421.

Zhao, G., Webber, H., Hoffmann, H., Wolf, J., Siebert, S., Ewert, F., 2015. The implication of irrigation in climate change impact assessment: a European wide study. Global Change Biology 21, 4031-4048. 